\title{
Evolutionary drought patterns over the Sahel and their teleconnections with low frequency climate oscillations
}

\author{
Christopher E. Ndehedehe ${ }^{\mathrm{a}, *}$, Nathan O. Agutu ${ }^{\mathrm{b}}$, Vagner G. Ferreira ${ }^{\mathrm{c}}$, Augusto Getirana ${ }^{\mathrm{d}, \mathrm{e}}$ \\ ${ }^{a}$ Australian Rivers Institute and Griffith School of Environment 6 Science, Griffith University, Nathan, Queensland \\ 4111, Australia. \\ ${ }^{b}$ Department of Geomatic Engineering and Geospatial Information Systems JKUAT, Nairobi, Kenya. \\ ${ }^{c}$ School of Earth Sciences and Engineering, Hohai University, Nanjing, China \\ ${ }^{d}$ Hydrological Sciences Laboratory, NASA Goddard Space Flight Center, Greenbelt, MD, USA \\ ${ }^{e}$ Earth System Science Interdisciplinary Center, University of Maryland, College Park, MD, USA
}

\section{Abstract}

The need for ideal drought metrics to explore the impacts of climate variability drivers on drought intensity and characteristics is essential to provide support that leads to optimizing existing templates on risk mitigation in drought-prone regions. The main aim of this study therefore is to improve contemporary understanding on the evolutionary patterns of historical drought over the Sahel (1901-2014) and the large-scale processes that drive its variability using the SPEI (standardized precipitation evapotranspiration index) and SPI (standardised precipitation index). Historically, the distributions of SPEI and SPI are generally quite similar with fairly strong correlations ranging from 0.80 to 1.0 around the central Sahel. The dissimilarity between SPI and SPEI in some regions however, suggest the influence of changing land surface conditions and the need to incorporate biophysical indicators to support the accounting process that aid the understanding of drought impacts and its cascading effects. Furthermore, SPEI and SPI confirm that the worst drought during the 20th century over the Sahel occurred between 1982 and 1985, affecting more than $90 \%$ of the region while the 1950s remained the wettest on record. However, between 2005 and 2015, drought episodes and their intensities have diminished over the Sahel. In the assessment of the coupled relationship of seven climate modes with drought evolutions, SPEI was more associated with Atlantic Multi-decadal Oscillation-AMO $(r=0.66)$ and Pacific Decadal Oscillation $(r=-0.53)$ unlike the SPI. A predictive multivariate model confirms the AMO is a strong driver of drought events and in addition, highlights the multi-scale climate influence in the Sahel.

Keywords: Pacific decadal oscillations, Food security, Rainfall, SPI, SPEI, Atlantic multi-decadal oscillations

\footnotetext{
${ }^{*}$ Corresponding author

Email address: c.ndehedehe@griffith.edu.au (Christopher E. Ndehedehe)
} 


\section{Introduction}

While the interest of relevant stakeholders in climate change is on the rise because of the need to address challenges related to water security and economic growth, the debate on the continued influence of atmospheric circulation features, warming of the tropical oceans, and indices of climate variability on hydro-meteorological processes is ongoing (e.g., 8, 65, 63, 5, 75, 58, 6, 23, 74). The catalogue of devastating impacts, including crop failure, loss of freshwater stocks, low gross domestic product (GDP), food insecurity, and loss of national income due to extreme droughts have been highlighted in some reports (see, e.g., 89, 52, 66, 83, 92, 16, 92, 53, 82, 14). Drought is slow and difficult to predict because of the overarching complexities associated with its causes, duration, magnitude, and timing on different temporal and spatial scales (see, e.g., 40, 98, 20, 76). Hence, the knowledge of drought characteristics and climatic processes connected with the variability of extreme drought events could provide support that leads to optimizing existing templates on risk mitigation in drought-prone regions, and in the evaluation of the cascading impacts of droughts on a broad range of ecosystem services.

In this era of complex interaction in landscape processes, non-climatic factors such as large scale human water withdrawals from underground reservoirs are known to interfere with the propagation process of drought characteristics and intensity (meteorological to hydrological) (43). It has been argued that land use change and increased water abstraction will play a role on future changes to drought while human-induced climate change is projected to drive large-scale ocean-atmospheric processes (e.g., 40). As combined human and climate factors could increase the frequency, variability, and even duration of drought intensity, further assessment of drought evolution is warranted to improve contemporary understanding of the processes that drives its variability on a large-scale.

In several African sub-regions such as East and West Africa, the impacts of droughts on agriculture create a plethora of risks and key challenges for the hydro-power sector, food and water security because of the heavy reliance on rainfall for several ecosystem functions (see, e.g., 61, 3, 92). Although there is an increasing discussion on the use of groundwater as an alternative freshwater resource to cushion the impacts of dry years and perhaps droughts on local communities in the semi arid West African Sahel (e.g., 105, 62), the recent account of drought impacts in Kenya ${ }^{1}$, which indicates more than 10 deaths due to hunger and about one million people being devastated by hunger and lack of water is an example of the risk and climate-induced calamity in the region. Added to the local agitations and inter-state tensions created by limited and shared water

\footnotetext{
${ }^{1}$ https://www.trtworld.com/africa/nearly-one-million-drought-hit-kenyans-at-risk-of-starvation-25088
} 
resources, armed conflicts as is now the case in the Lake Chad basin will amplify the vulnerability of rural agro-communities to poverty (60). Even the regions and distant populations that indirectly depend on the water resources of Africa could be victims of far-reaching impacts of limited alimentation caused by drought through trade disruption and price volatility (28). As the Sahelian droughts have also been attributed to the perturbations of the surrounding oceans and humaninduced climate change (27), assessing evolutionary drought patterns is essential and can improve our knowledge of drought events and the important processes of oceanic variability associated with its spatio-temporal variability.

As economic output and national income are quite sensitive to hydro-climatic variability (e.g., $89,34,16,13,102)$, non-industrialized regions with limited resources and who sometimes benefit from emergency relief and intervention funds from developed economies are most often the recipients of terrific social and economic impacts of climate change. While more diagnostic studies are warranted to increase drought preparedness and support specific policy frameworks and complementary interventions (e.g., 81), the use of machine learning (Deep Neural Networks) has recently been introduced to provide knowledge that can support conflict resolution between farmers and pastoralists in the semi-arid Sahel (77) who tend to strive for the limited water resources in the region. Obviously, the Sahel has been the center of several eco-hydrological and hydro-meteorological studies (see, e.g., 62, 85, 33, 41, 49, 36, 48), with considerable reports focused on the impact of oceanic phenomena on precipitation patterns (see, e.g., 24, 50, 71, 54, 26). However, the evolutionary patterns of historical drought episodes in the region and their teleconnections to low frequency climate oscillations is undocumented. Arguably, the interactions of such influence with circulation features and mesoscale convective systems, among other climate phenomena (e.g., 25, 26, 46) have direct repercussions on hydrological processes. Indeed, the long history of unfavourable hydrological conditions of the West African Sahel provides a basis to diagnose the contributions of these oceanic factors on drought evolutions in the region (65).

Given the strong land-atmosphere interactions of semi-arid tropical areas (e.g., 42), the other non-trivial challenge is on identifying a suitable drought indicator that captures this large scale processes more effectively. Indeed, indicators and metrics are at the center of numerous assessments, including those used to designate human development and environmental performance. The changing patterns of local precipitation, land surface and catchment characteristics in some regions have therefore triggered the need for ideal metrics to explore drought intensity. For example, the long-term decline of rainfall in the North China Plain was linked to observed decline in evapotranspiration, which has been recommended as a key variable in agricultural drought monitoring 
and indicator for early warning of food insecurity during drought periods $(67,96,15)$. The use of standardised precipitation index (SPI, 51) could be limited in arid regions because of its inability to account for evapotranspiration, which is a critical source of water loss and soil moisture condition, a key metric of water availability. One could therefore argue that for reasons that are not unconnected to climate change-induced extreme high temperatures, which are typical climate characteristics of such areas, the use of SPI may be restricted. For instance, leafing and reproductive phenophases in arid climates such as the Sahel (Fig. 1a) are more impacted by trends in land surface temperature as opposed to rainfall (e.g., 90). As rainfall is not a direct indicator of freshwater water availability (e.g., 67, 108, 18), this was the basis for the recommendation of the joint use of composite evapotranspiration-based index and other hydrological units to assess climate-driven influence on water availability (68). In addition to this, globally, key processes of inter-annual variability such as the ENSO (El-Niño Southern Oscillation), and other inter-decadal and multi-decadal global climate oscillations have been linked to considerable changes in surface hydrology and extreme drought events (e.g., 30, 64, 4, 83, 44, 11, 91).

The main aim of this study therefore is to assess the evolutionary drought patterns $(1901-2014)$ over the West African Sahel (Fig. 1a-b) and their teleconnections with low frequency climate oscillations during the last three decades. For the first time we (i) compare a multi-scaled standardized index, the standardized precipitation evapotranspiration index (SPEI 103, 104) to empirical probability-derived SPI (e.g., 29, 35) in the characterization of droughts over the Sahel region and (ii) assess the coupled relationship of multi-scale climate modes (Section 2.3) with SPEI and SPI using a suite of climate modes as predictors in a multivariate framework. More details on the method development and analysis of the spatio-temporal characteristics of SPEI and SPI are highlighted in subsequent sections.

\section{Data and study region}

\subsection{Study region}

The Sahel is a semi-arid region with about 60 million people and encompasses West and northcentral Africa extending from Senegal eastward to Chad and Sudan (east). Although Agnew and Chappell (2) argue that the Sahel region is not well demarcated, a general geographic description of the region is that it is seated in the transitional zone between the Sahara desert to the north and the sudano and humid savannas to the south. The Sahel region analysed in this study (Longitude $10 \mathrm{E}$ to $20 \mathrm{E}$ ) begins from Mali ending in Chad and covers about six semi-arid West African countries (Fig. 1a), including areas Agnew and Chappell (2) categorised as continental Sahel region (Mali, 


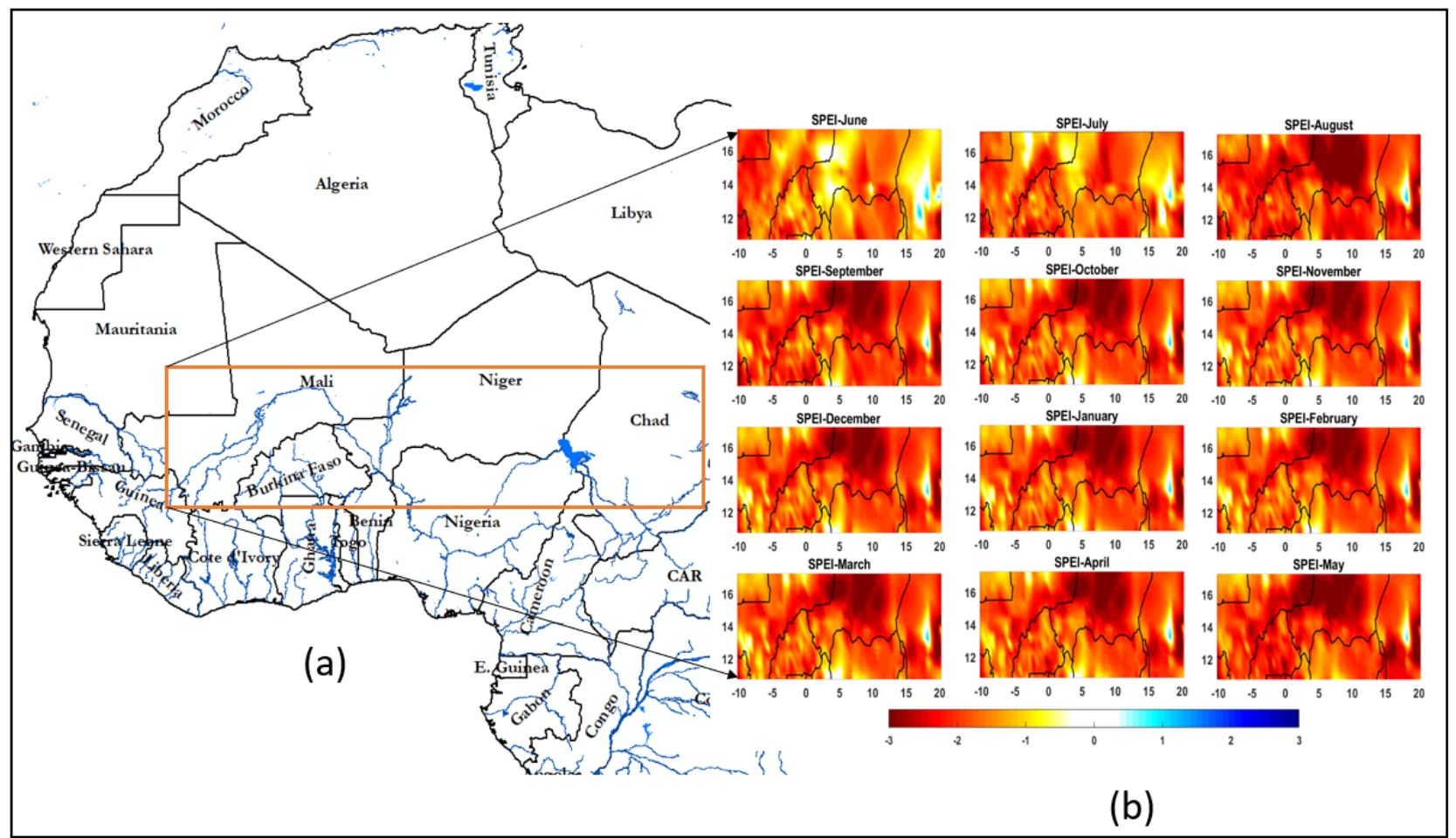

Figure 1: Study area showing countries in the African sub-region where the brown box is the (a) Sahel region analysed in this study while (b) is the distribution of standardized precipitation evapotranspiration index during the notorious droughts episodes of $1984-1985$ period in the region. Interpretation of drought thresholds in (b) is based on McKee et al. (51) threshold and is summarised in Table 1. Hydrological units (blue lines and polygons), i.e., rivers, lakes, and water ways in the West African Sahel are also indicated.

Burkina Faso and Niger). In the Sahelian countries, rainfall varies from less than $200 \mathrm{~mm} /$ year towards higher latitudes to about $400-600 \mathrm{~mm}$ at the southern boundary (e.g., 64, 2). Annual rainfall pattern, which is regulated by the migration of the Inter-tropical Convergence Zone occurs between June and September, with maximum rainfall occurring in August. Temperatures range from $32^{\circ}$ to $35^{\circ}$ during the months of April to July (e.g., 27).

\subsection{Precipitation}

The Global Precipitation Climatology Centre (GPCC, 88, 10) data was used to compute standardised precipitation index (SPI). The data is a well known reference precipitation data with global coverage that provides reliable monthly observations of global land-surface precipitation, covering the period from 1901 to 2014 . The $1.0^{\circ}$ x $1.0^{\circ} \mathrm{GPCC}$ data was downloaded from the GPCC data portal (www.ftp.dwd.de/pub/data/gpcc/html/downloadgate.html). The GPCC is a widely used observational reference data that was found suitable for agricultural drought characterization in East Africa and consistent with Climate Research Unit (CRU) observations over the Congo basin $(63,3)$. Although a fall in the number of available gauges may affect our ability 
to track future changes in precipitation (95), the GPCC Full Data product used here is the most commonly used product as it relies on observations from more than 85,000 stations worldwide. Even though uncertainties in the GPCC data over the Sahel is not available in existing literature, GPCC was recently used as reference object in the assessment of 30 available global precipitation data sets, including gauge-based observations, satellite, and reanalysis (95). While the distribution of gauges are expected to vary in time and space, especially in regions with poor investment in meteorological stations, GPCC is still nonetheless, the largest gauge-observation data available globally. The distribution of historical rainfall gauge stations over Africa and the changes over time is covered in the recent work by Nicholson et al. (75).

\subsection{Multi-scaled standardized index}

The standardized precipitation evapotranspiration index (SPEI) combines precipitation and temperature data in a water balance framework (see, 103, 104). From its multi-scalar character and the inclusion of the effects of variations in temperature on drought assessment, the SPEI is an important drought metric for evaluating the impacts of drought under a global warming scenario. The rainfall component of the SPEI $\left(0.5^{\circ} \times 0.5^{\circ}\right.$ spatial resolution $)$ used in this study was calculated from the CRU derived precipitation (i.e., version 3.23 CRU TS dataset). Although the multi-scalar nature of SPEI enhances its potential in identifying several drought episodes (104), exploring its suitability over the Sahel to understand the complex eco-hydrological response to precipitation deficit is essential. This SPEI data covers similar period as the GPCC-based precipitation and is freely available online (http://digital.csic.es/handle/10261/153475). The quest for drought metrics derived from multiple climate variables has resulted in the growing application of SPEI in drought characterisation in recent times (see, e.g., 69, 93, 6, 57).

\subsection{Climate modes}

The climate modes used in this study are El-Niño Southern Oscillation (ENSO), Indian Ocean Dipole (IOD), Atlantic Multi-decadal Oscillation (AMO), Atlantic Meridional Mode (AMM), Pacific Decadal Oscillation (PDO), Quasi-Biennial Oscillation (QBO), and Maiden Julian Oscillation (MJO). These datasets were downloaded from NOAA's data portal (http://www.ncdc.noaa.gov/ teleconnections) and were used to identify the coupled variability of global climate on the evolutionary patterns of the Sahelian drought. The influence of these oscillations on the variability of West African rainfall and other African subregions have been reported (e.g., 8, 64, 4, 31) but still largely debated in some of the studies highlighted in Section 1. The detailed description of 
these climate modes and how they were generated are available on NOAA's online data repository indicated above.

\section{Methods}

\subsection{Standardized precipitation index vs standardized precipitation evapotranspiration index}

In this study, a multi-scaled standardized index, the SPEI (103, 104) was used as a drought indicator. This SPEI data was estimated based on a water balance approach as the difference between precipitation $(P)$ and $P E T$ (potential evapotranspiration), i.e., $\delta=P-P E T$. The computed values of $\delta$ are cumulated on time scales as (104),

$$
\delta_{n}^{k}=\sum_{i=0}^{k-1}\left(P_{n-i}-P E T_{n-i}\right), n \geq k
$$

where $k$ is the cumulated time scale and $n$ is the calculation number. This cumulated time series are thereafter fitted with a log-logistic probability distribution function. The SPEI data was compared to the 12 month-cumulated time series of standardised precipitation index (SPI, 51) in the characterization of droughts over the Sahel region. The accumulation period of 12 month allows for the capturing of drought characteristics (e.g., percentage of affected areas), hydrological drought/and or impact on hydrological stores (e.g., soil moisture) and to cushion the effects of correlation with low frequency climate oscillations. As the Sahel region is typically arid, we assume that a drought condition occurs when the drought index is consistently negative and reaches a value of -1 . The adopted threshold supports the characterization of hydrological drought (decreased precipitation that impacts on streamflow, reservoir and lake levels, soil moisture, and groundwater recharge) episodes in the region based on the SPI 12-month aggregation (63). The different drought categories used for interpretation, which correspond to the thresholds used in SPI are highlighted in Table 1. The SPI implemented here uses an empirical probability method to derive a non-parametric standardised index following Farahmand and AghaKouchak (29) and Hao and AghaKouchak (35) and is given as

$$
p\left(x_{j}\right)=\frac{m_{j}-0.44}{n+0.12},
$$

where $n$ is the sample size, $m_{j}$ represents the rank of non-zero precipitation data (i.e., observed values) starting from the smallest while $p\left(x_{j}\right)$ is the corresponding empirical probability. Eqn 2 is transformed to a standardised index as

$$
S I=\phi^{-1}(p)
$$


Table 1: Drought thresholds based on McKee et al. (51) classification system. The various drought intensities over the Sahel are based on these thresholds.

\begin{tabular}{ll}
\hline Description & Threshold \\
\hline Extreme wet & +2.0 and above \\
Very wet & +1.5 to +1.99 \\
Moderately wet & +1.0 to +1.49 \\
Near normal & -0.99 to +0.99 \\
Moderate drought & -1.0 to -1.49 \\
Severe drought & -1.5 to -1.99 \\
Extreme drought & -2.0 or less \\
\hline
\end{tabular}

where $\phi$ is the standard normal distribution function and $p$ is the probability obtained from Eqn 2 . The various drought intensities (extreme, severe, and moderate) during the period and their aerial extent were estimated based on the thresholds highlighted in Table 1.

\subsection{Statistical analyses}

\subsubsection{Spatio-temporal drought patterns}

The use of multivariate techniques such as the principal component analysis (PCA, e.g., 38) to characterise drought evolutions was pioneered by Karl and Koscielny (39) and has since resulted in several applications of PCA in the spatio-temporal analysis of drought patterns globally (see, e.g., 3, 37, 9, 86, 12). Not only is it useful in the analysis of meteorological and geophysical observations (e.g., 59, 85, 55), it is now an effective tool in diagnosing the impacts of large scale oceanic atmospheric predictors, atmospheric blocking, and climate teleconnection patterns on hydro-meteorological patterns (e.g., 63, 56, 45, 73). Consider a matrix of SPI and SPEI values as $\mathbf{X}_{S P E I / S P I}=\left[x\left(p_{k}, t\right)\right]$ where $p_{k}$ is space locations; $\mathrm{k}=1,2, \ldots, N x$, which is the number of spatial locations for $\mathbf{X}_{S P E I / S P I}$, and $t$ is the monthly time step from $1901-2014$. The temporal and spatial patterns of SPEI and SPI at a 12-month scale will be decomposed as,

$$
\mathbf{X}_{S P E I / S P I}(t)=\sum_{k=1}^{N} a_{(k)} \mathbf{p}_{k}
$$

where $a_{(k)}(\mathrm{t})$ is the standardised score (temporal patterns) also called expansion coefficient, $\mathbf{p}_{k}$ is the corresponding spatial pattern (or empirical orthogonal functions-EOF loading). The dominant modes are the first few pairs obtained, which usually explains the highest variability in the data and is usually an approximation of large scale average while the remaining modes describe other 
variabilities, e.g., large scale contrasts with dipoles and loadings (e.g., 56). For the purpose of physical interpretability, we have focused on two spatio-temporal modes of SPEI and SPI over the Sahel.

\subsubsection{Multi-scale climate influence on droughts evolutions}

The partial least squares regression (PLSR, e.g., 17, 21) model was used to assess the coupled relationship of multi-scale climate modes with SPEI and SPI. As opposed to the PCA method, PLSR looks for latent vectors, which performs a simultaneous decomposition of independent variable, $\mathbf{X}$ and response variable $\mathbf{Y}$ (e.g., 47, 107). These PLSR components are so determined to maximize the covariance between the two variables whilst complying with certain orthogonality and normalization constraints (21). Consider a simple formulation of the PLSR model (e.g., 17) where the data elements $\mathbf{x}_{i}=\left[x_{i 1}, x_{i 2}, x_{i 3} . ., x_{i p}\right]^{\prime} \in \Re^{p}(i=1,2,3, . ., n)$ with $n$ as the observation samples and $\mathbf{y}_{i}=\left[y_{i 1}, y_{i 2}, y_{i 3} . ., y_{i q}\right]^{\prime} \in \Re^{q}(i=1,2,3, . ., n)$ where $n$ is the corresponding dependent samples. Then the independent variable, $\mathbf{X}=\left[\mathbf{x}_{1}, \mathbf{x}_{2}, \mathbf{x}_{3} . ., \mathbf{x}_{n}\right]^{\prime} \in \Re^{n \times p}$ and the response variable $\mathbf{Y}=\left[\mathbf{y}_{1}, \mathbf{y}_{2}, \mathbf{y}_{3} . ., \mathbf{y}_{n}\right]^{\prime} \in \Re^{n \times q}$. The centered (i.e., removing the mean) data matrices $\mathbf{X}$ and $\mathbf{Y}$ are decomposed as (e.g., 17, 107),

$$
\mathbf{X}_{n \times p}=\mathbf{t}_{n \times 1} \mathbf{p}_{p \times 1}^{\prime}+\mathbf{E}_{n \times p}, \quad \mathbf{Y}_{n \times q}=\mathbf{u}_{n \times 1} \mathbf{q}_{q \times 1}^{\prime}+\mathbf{F}_{n \times q},
$$

where $\mathbf{t}$ and $\mathbf{u}$ are latent vectors for the $n$ observations, $\mathbf{p}$ and $\mathbf{q}$ are the loading vectors while $\mathbf{E}$ and $\mathbf{F}$ are the residual matrices. Additional formulation details and multivariate calibration are available in the literature (e.g., 17, 47, 107, 21) as they are only briefly stated here. The assessment of climate influence on the evolutions of SPEI and SPI over the Sahel based on the PLSR formulation was obtained as

$$
\mathbf{Y}=\mathbf{X} \beta+\mathbf{F},
$$

where $\beta$ is the PLSR coefficients, $\mathbf{X}_{\text {Climate modes }}$ and $\mathbf{Y}_{S P I / S P E I}$ are the predictor data matrix and response variables, respectively. The prediction of SPEI and SPI using these climate modes was based on retained seven partial least square components. Before the comparison of predicted drought indicators with the observed, the local least-squares polynomial approximation-based filter of Savitzky and Golay (87) was applied to filter the climate modes, which have been normalised using their standardised z-score. This is essential to to cushion the effect of noise and moreso place the predictors on the same normalisation scale as the predictands (SPI and SPEI), which were aggregated on a 12-month scale. 

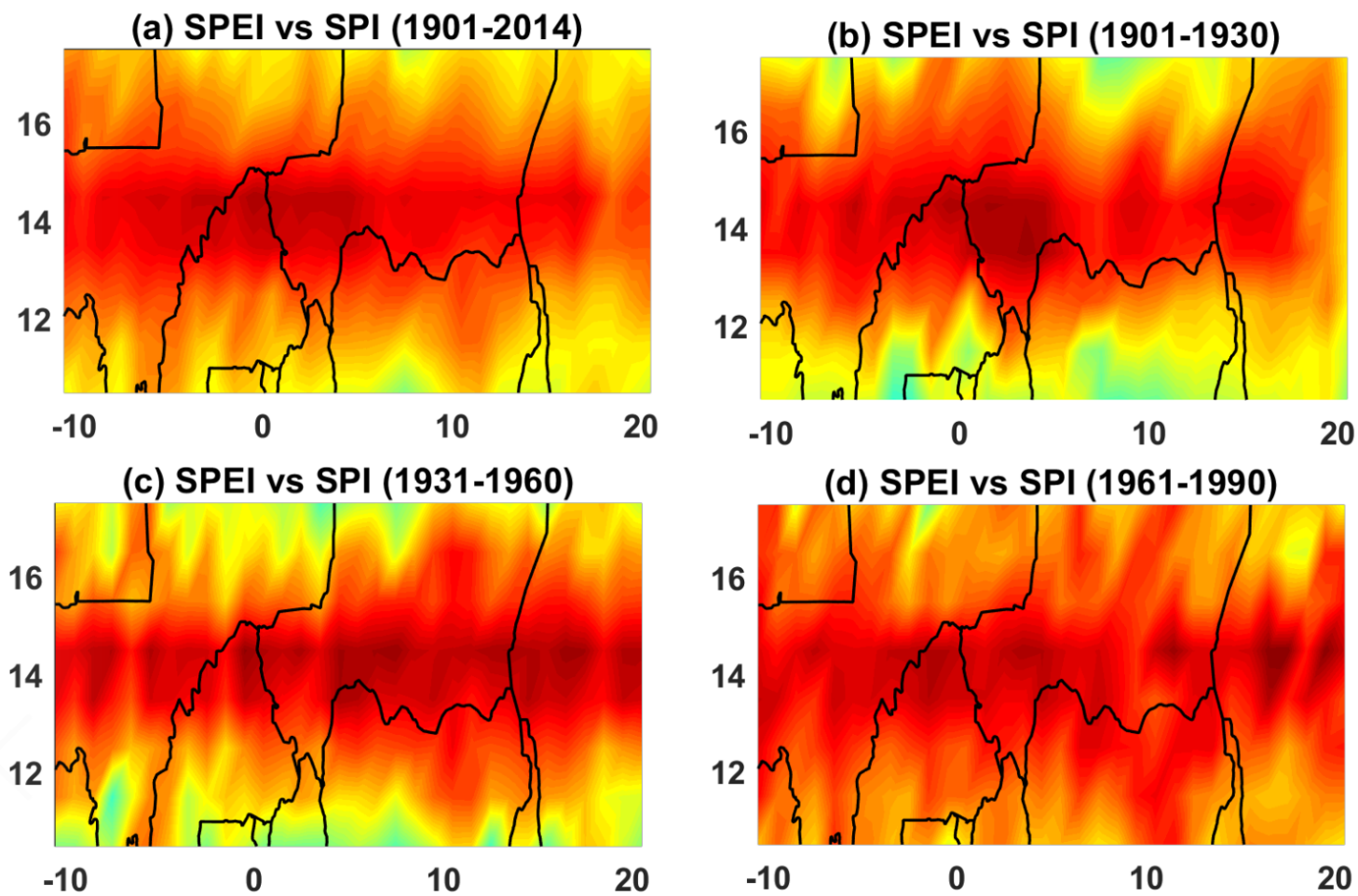

(e) SPEI vS SPI (1991-2014)
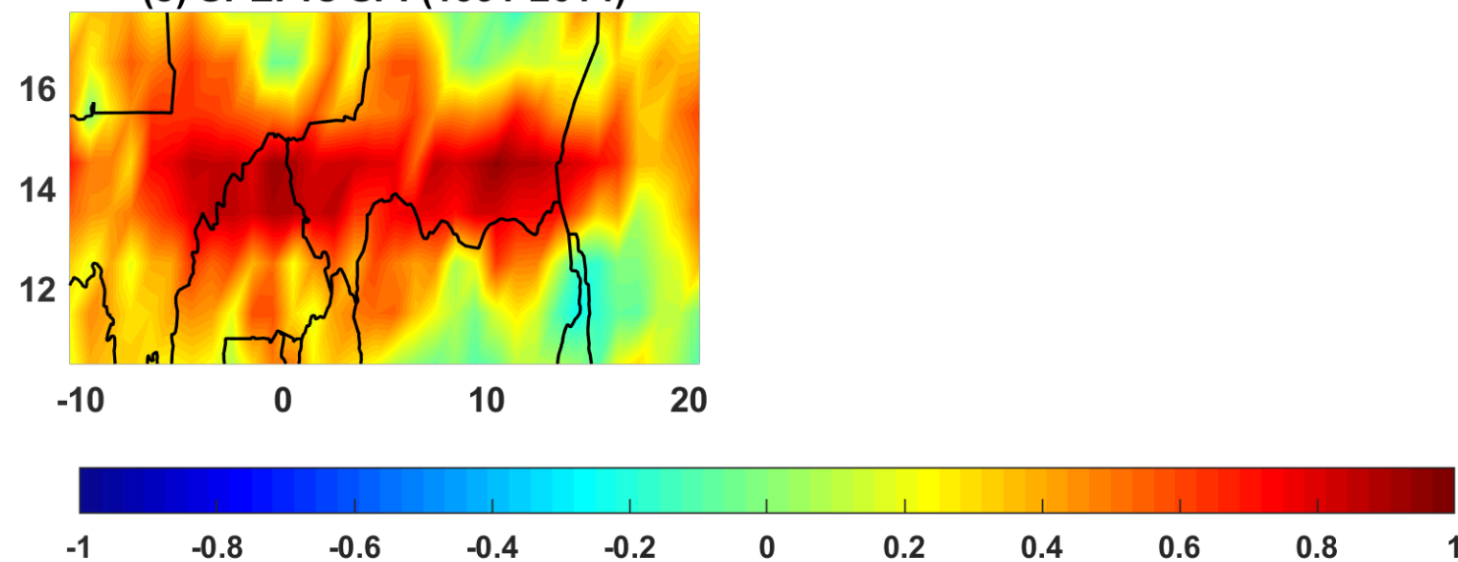

Figure 2: Spatial distribution of correlation coefficients between SPI and SPEI over the Sahel during different climatological windows. (a) The relationship between SPI and SPEI during the entire period while (b-e) are the association between SPEI and SPI in different climatological periods (30-year interval) except for (e) with a 23-year interval. Note that the latitudes (y-axis) and the longitudes (x-axis) are indicated on each plots. This format is also used in subsequent figures.

\section{Results}

\subsection{Evolutionary patterns of SPI and SPEI}

During the last century, the spatio-temporal distributions of SPEI and SPI over the West African Sahel were generally quite similar for much of the central Sahel, with fairly consistent and moderately strong correlations (Fig. 2a). However, the spatial distribution of correlation coefficients 
Table 2: Percentages (\%) of observed variance explained by leading SPEI and SPI orthogonal modes during the century (1901 - 2014) and different climatological windows within the century.

\begin{tabular}{ccccccc}
\multicolumn{2}{l}{ PCA modes } & $1901-1930$ & $1931-1960$ & $1961-1990$ & $1991-2014$ & $1901-2014$ \\
\hline \multirow{2}{*}{ PC 1 } & SPI & 37.8 & 46.7 & 57.9 & 35.8 & 42.1 \\
& SPEI & 39.4 & 49.9 & 55.3 & 37.1 & 45.1 \\
\multirow{2}{*}{ PC 2 } & SPI & 12.7 & 8.2 & 5.9 & 7.9 & 8.2 \\
& SPEI & 11.8 & 9.5 & 6.7 & 11.4 & 7.6 \\
\hline
\end{tabular}

between SPI and SPEI over the Sahel during four climatological windows (1901-1930; 1931-1960; 1961 - 1990; and 1991 - 2014) are significantly different (Figs. 2b-e). The 1961 - 1990 period (Fig. 2d) was characterised, for example, by a much wider spread of relatively stronger positive correlations (SPEI vs SPI) in all the Sahelian countries as opposed to other climatological periods (Figs. 2b-c and e). The dissimilarity and poor association between SPI and SPEI in some regions, especially during the 1991-2014 period are obvious (Figs. 2b and e) and could suggest the influence of changing land surface conditions caused by strong dynamics in evaporative demand and surface drying. Evidence from region-specific studies on climate change induced drought have confirmed the direct impact of warming temperatures and anthropogenic warming as significant drivers of droughts through increase in evaporative losses (e.g., 19). But generally, the southern sections of Niger, Mali and northern Burkina Faso are sub regions where these indicators are consistent and well associated (Figs. 2a-e) all through the entire period. This is also consistent with their leading spatio-temporal evolutions in the last century (SPEI-EOF and SPI-EOF, Fig. 3).

However, the statistical decomposition of SPEI and SPI during the four climatological periods (following the groupings in Fig. 2) highlighted their intrinsic temporal and spatial differences (Figs. 4-5). The temporal and spatial evolutions of both drought indicators over the West African Sahel are captured in two orthogonal modes of variability for the entire period (Fig. 3). The leading modes (spatial and temporal) of both drought indicators are centered over the Sahel while the second modes of variability are those within the Lake Chad basin, the region encompassing sections of Chad, Niger, and north-east Nigeria (Fig. 4). Table 2 summarises the observed variability accounted for in the evolutions of leading SPEI and SPI modes during the entire period and different climatological windows. From Table 3, the temporal and spatial patterns of both SPEI and SPI are largely similar with their temporal patterns indicating strong correlation $(r=0.93)$. But the spatio-temporal variability during the four climatological periods are notably different. As indicated in Table 3, the temporal series of the dominant SPI and SPEI modes (SPEI-1 and SPI-1, 

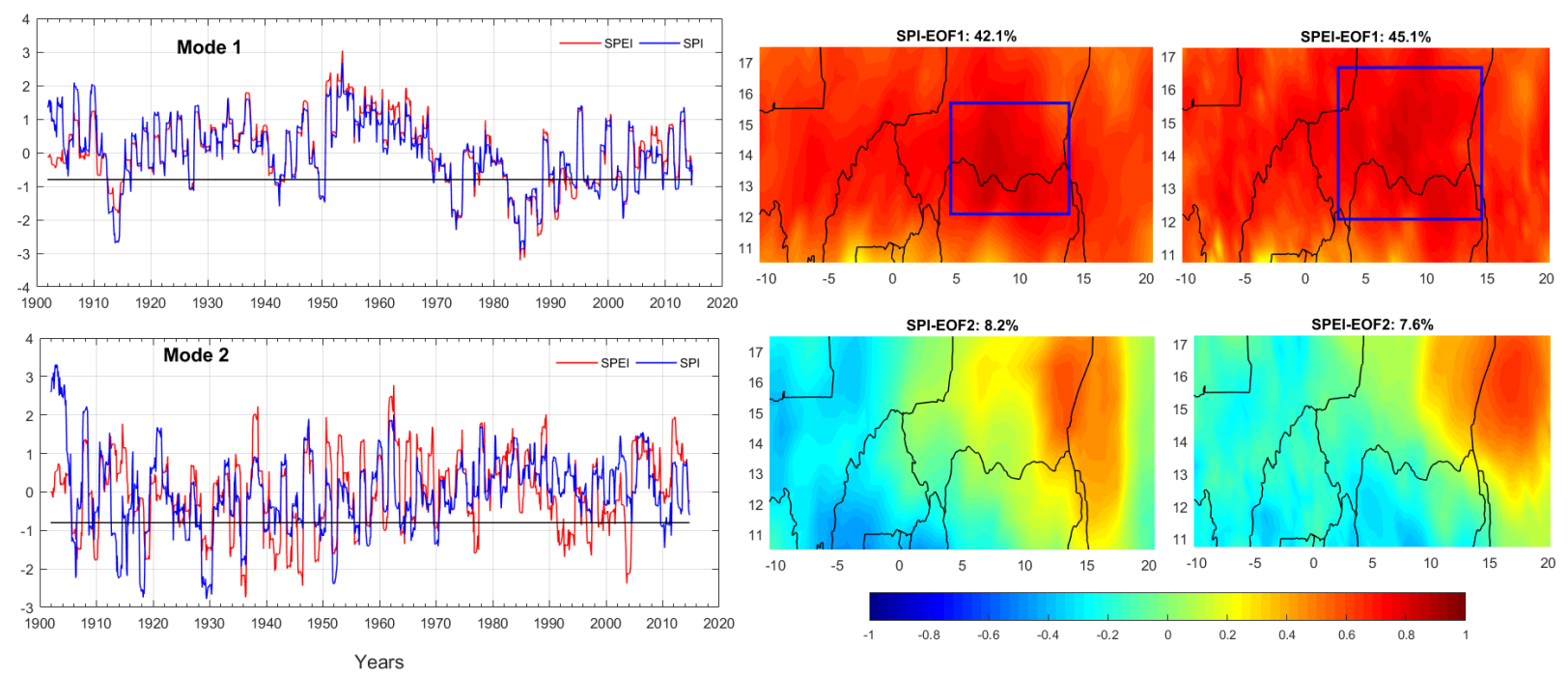

Figure 3: Spatial and temporal patterns of SPI and SPEI over the Sahel region during the 1901 - 2014 period. The EOFs are loadings showing spatial patterns of SPI/SPEI (left) while the corresponding principal components (PCs) are temporal variations (right). The actual SPEI and SPI values are jointly derived from their spatial and temporal patterns. The black solid line is drought threshold based on the classification in Table 1. The insert on the spatial maps show locations in Niger with the highest SPEI and SPI loadings during the entire period.

(Fig. 5) were more associated $(r=0.99)$ in the $1961-1990$ period and coincides with the period when the strongest variability was observed by both SPEI (57.9\%) and SPI (55.3\%). The lowest variability was observed for SPEI (39.4\%) and SPI (37.8\%) between 1901 and 1930, the period during which their temporal series were less associated $(r=0.76)$. Even their spatial patterns during the same period $(1901-1930)$ are significantly different with SPI showing stronger spatial loadings in Niger (Fig. 4). This implies stronger extremes in SPI, that is, drought/wet events were more severe and wide spread as opposed to the SPEI (Fig. 4). But this was reversed during 1960 - 1990 period as spatial loadings were relatively stronger in SPEI in Niger and northern Nigeria and much of the Sahel than SPI (SPEI-EOF and SPI-EOF, Fig. 5). Note that during this same climatological period both indicators had considerable association (Fig. 4 and Table 3). But there has been a clear inconsistency between the two indicators in the spatial and temporal patterns of their second modes for all climatological periods (Figs. 4-5). Their temporal association during the $1931-1960$ period is moderately strong $(r=0.75)$ and lowest $(r=0.20)$ between $1991-2014$ (SPEI-2 and SPI-2, Figs. 4-5 and Table 3). Again, the temporal relationship between these indicators and their corresponding spatial patterns is found to be rather dynamic, similar to Fig. 2.

\subsection{Drought intensities and characteristics during the 1901-2014 period: SPI vs SPEI}

The 1950s was one of the wettest periods on record in the Sahel while persistent extreme droughts were observed during the 1910 - 1915, 1972 - 1975 and 1982 - 1985 periods (Mode 1, 


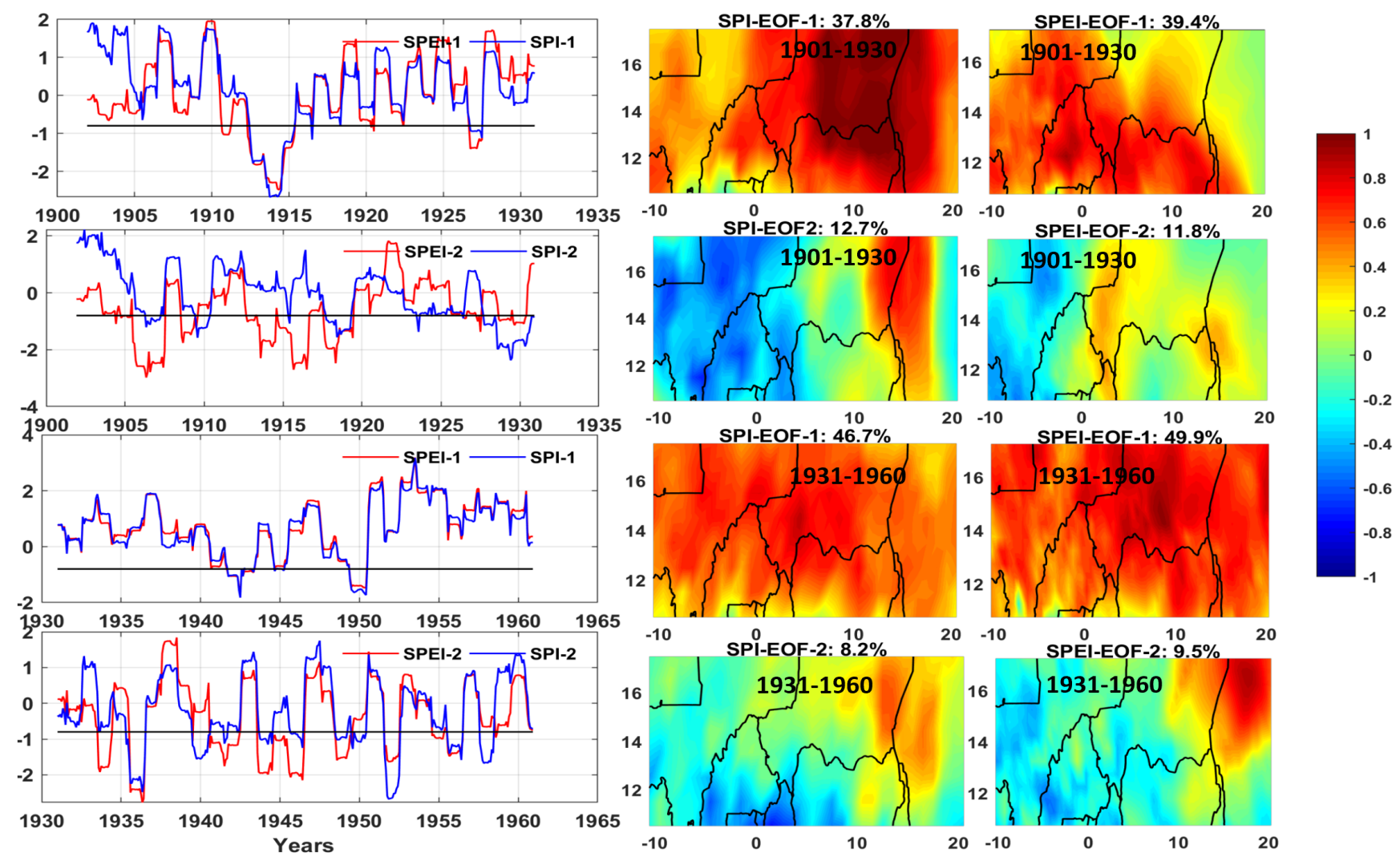

Figure 4: Spatial and temporal patterns of SPI and SPEI over the Sahel region for climatological periods between 1901 and 1960. The EOFs (spatial) and their corresponding PCs (temporal) are constructed similar to Fig. 3.

Fig. 3). Extreme wet events corresponding to ENSO years can also be seen in the SPEI and SPI patterns (Fig. 5). However, the notable 1980 droughts were the worst in the last century, given their long duration and persistence (Figs. 4 and 5). These drought events are well known and coincides with periods when large river basins in West Africa suffered loss of freshwater stocks, including alterations in river regimes in Sahelian countries $(62,49)$. The time series of SPEI and SPI in Fig. 3 shows that even though rainfall conditions later improved with considerable wetness in between during the last two decades, the wetness in the 1950s has still not been reached. In other words, despite the recovery and change in rainfall seasonality, mean anomalies are still well below the 1950 threshold indicated in Fig. 3.

The evolutionary patterns of droughts in terms of their characteristics and intensities (moderate, severe, extreme) in the Sahel have also been indicated (Figs. 6a-h). The temporal patterns of different drought intensities in the Sahel from both indicators (Figs. 6a-h) agree with the temporal distributions of SPEI and SPI over the West African Sahel as shown in Fig. 3. The predominance of extreme drought events from these indicators during the 1910-1915 and 1980-1985 periods show 
Table 3: Pearson correlation coefficients $(r)$ of SPI temporal series with those of SPEI during different climatological periods and the entire period $(1901-2014)$. Correlations are statistically significant at $\alpha=0.05$.

\begin{tabular}{lccccc}
\hline PCA mode & $1901-1930$ & $1931-1960$ & $1961-1990$ & $1991-2014$ & $1901-2014$ \\
\hline SPEI-1 vs SPI-1 & 0.76 & 0.98 & 0.99 & 0.89 & 0.93 \\
SPEI-2 vs SPI-2 & 0.26 & 0.75 & 0.60 & 0.20 & 0.52 \\
\hline
\end{tabular}

Table 4: Pearson correlation coefficients $(r)$ of dominant SPI and SPEI temporal series (SPEI-1 and SPI-1, Fig. 3) with climate teleconnections $(1980-2014)$. Correlations are statistically significant at $\alpha=0.05$ except for those marked with asterisks $(*)$.

\begin{tabular}{lccccccc}
\hline Drought indicator & AMO & AMM & ENSO & PDO & QBO & MJO & IOD \\
\hline SPEI & 0.66 & 0.47 & -0.34 & -0.53 & $0.01^{*}$ & -0.20 & $0.14^{*}$ \\
SPI & 0.55 & 0.38 & -0.28 & -0.46 & $0.05^{*}$ & $-0.15^{*}$ & $0.12^{*}$ \\
\hline
\end{tabular}
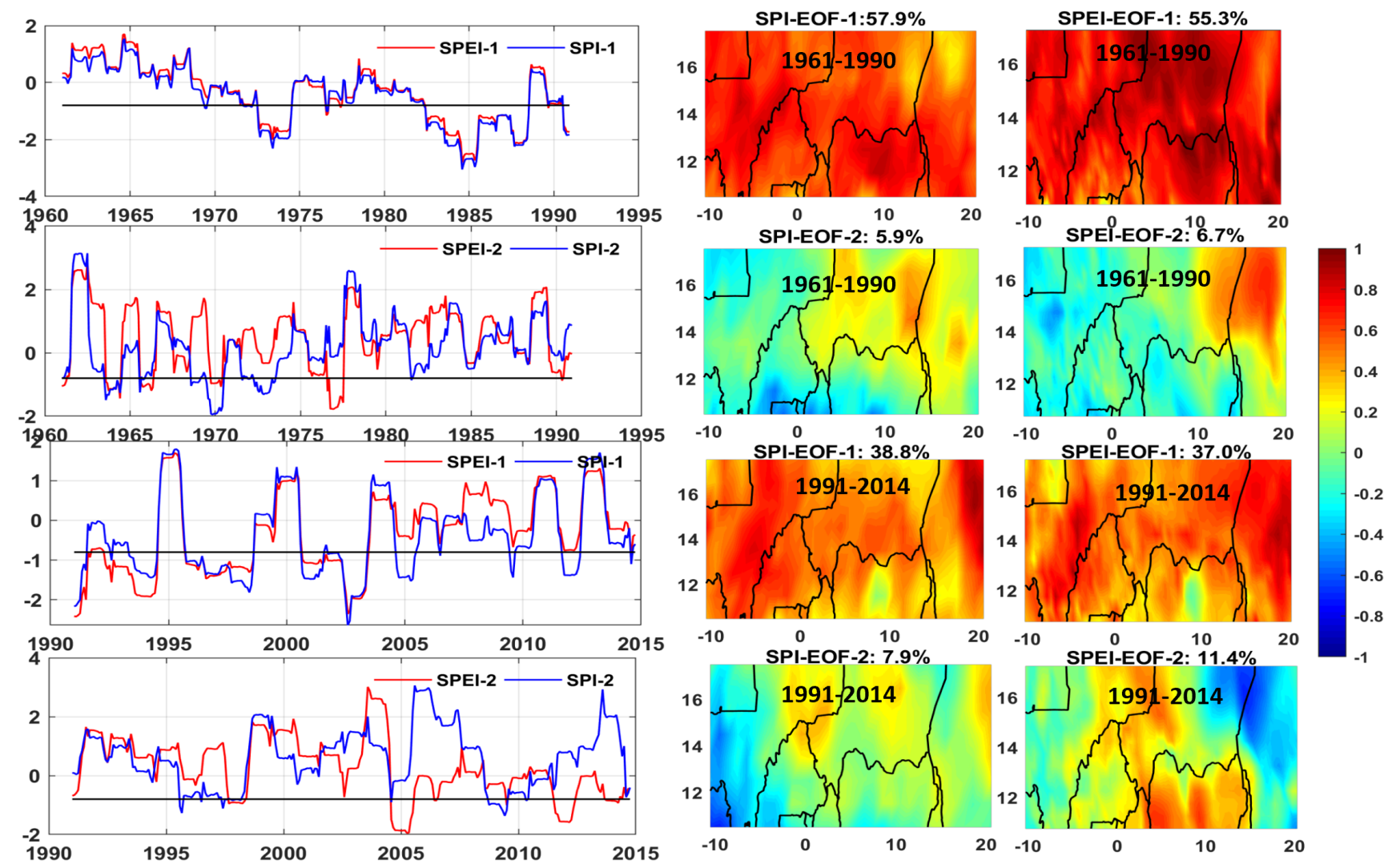

Figure 5: Spatial and temporal patterns of SPI and SPEI over the Sahel region for climatological periods between 1961 and 2015. The EOFs (spatial) and their corresponding PCs (temporal) are constructed similar to Fig. 3.

that more than $50 \%$ of the Sahel was affected (Figs. 6a, c, e, and g). The worst drought during the 20th century occurred between 1982 and 1985, affecting more than 90\% of the region between 1984 and 1985 (Fig. 7). The drought was also extreme between 1987/1988 affecting about 85\% (SPEI) 

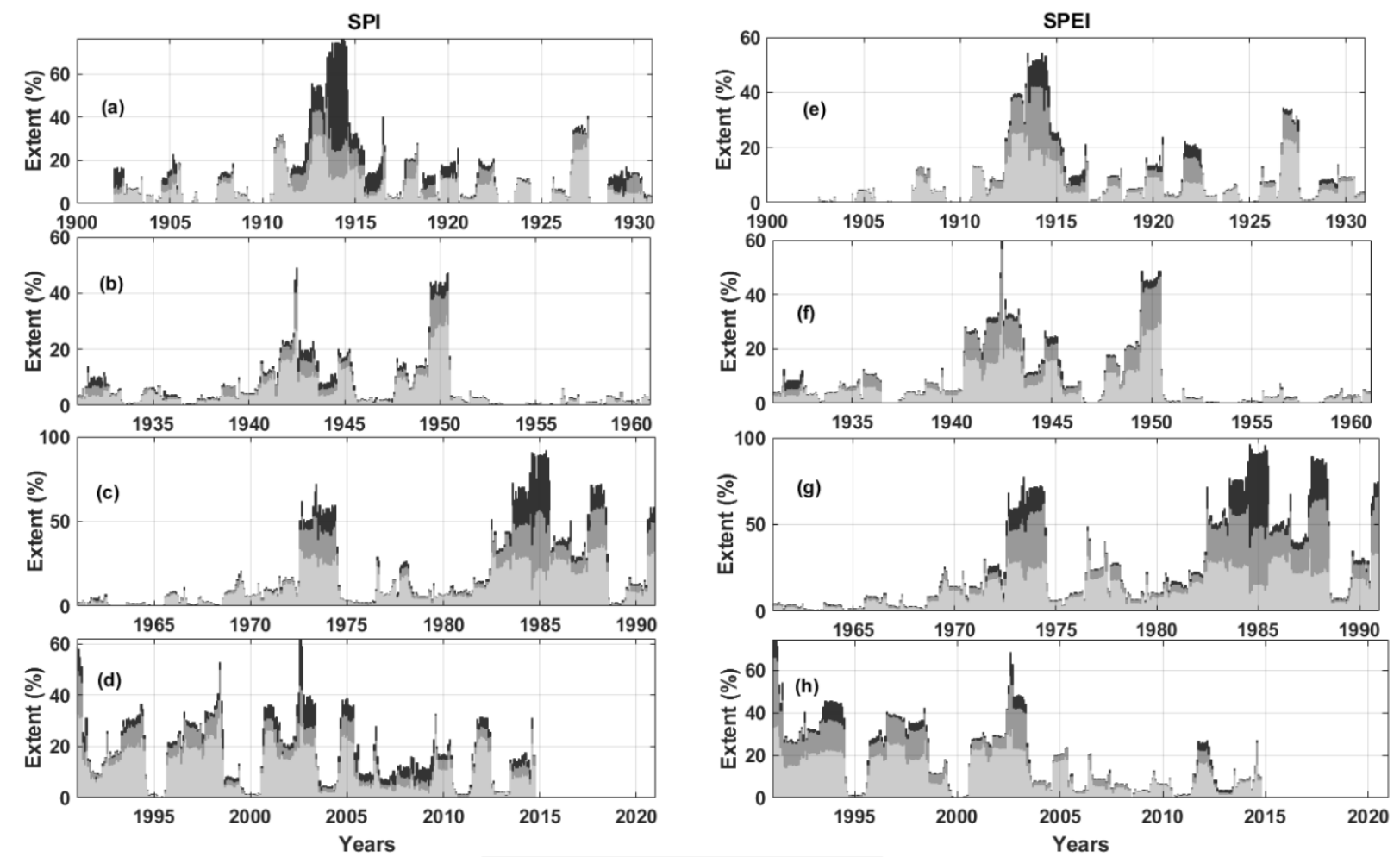

Figure 6: Drought extents over the West African Sahel between 1901 and 2014. The estimated drought extents for (a-d) SPI and (e-h) SPEI are described in terms of their intensity (moderate, severe, and extreme). The affected areas $(\%)$ are characterized based on the classification indicated in Table 1.

or $70 \%$ (SPI) of land areas (Figs. 6c and g). A critical consideration of the period between 1980 and 2015 show that drought episodes and their intensities have diminished and has varied less over the Sahel during the $2005-2014$ period (Fig. 6c-d and g-h, Table 2). Whereas these results are aligned with the popular notion of rainfall recovery in the region, the Sahel is still not as wet as the 1950 - 1960 period (Fig. 6b and f). We argue nevertheless, that comparatively, based on the evolving patterns of drought intensities after 2005, the Sahel is no doubt becoming wetter and aligns with past and emerging studies on the recovery of rainfall in the region (see, e.g., 70, 71, 85, 4). The decreasing intensity in extreme drought episodes can as well be deduced from the spatio-temporal patterns of SPEI-1 and SPI-1 of Fig. 3. Generally, the two indicators compare rather well in their characterisation of various drought intensities and estimation of affected areas. However, there are significant differences in their predicted extents of extreme drought during 1910 - 1915 (Figs. 6a and e) and 1980 - 1985 (Figs. 6c and g). Moreover, the considerable dissimilarity between SPEI and SPI in their estimated drought intensities during $2005-2015$ period is notable (Figs. 6d and h). The plenitude of severe and extreme droughts as estimated by SPI between 2005 and 2011 are in sharp contrast to the largely moderate drought events predicted by SPEI during the same 


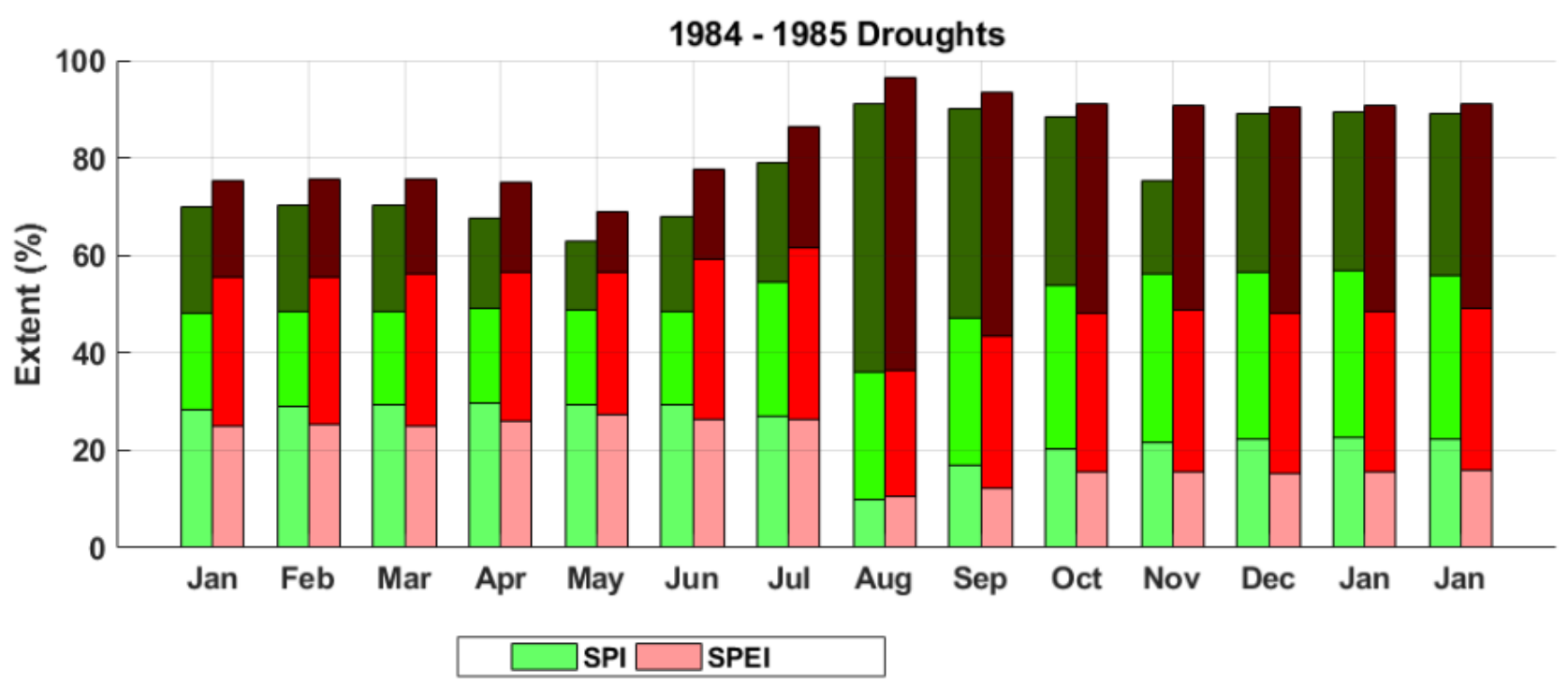

Figure 7: Analysis of areas under drought for the 1984-1985 period using the SPEI and SPI. This characterization is based on different drought intensity. That is, moderate (bottom layer in pink for SPEI and light green for SPI), severe (middle layer in red for SPEI and quetzel green for SPI), and extreme (top layer in maroon red for SPEI and deep or forest green for SPI) droughts. SPEI and SPI are also evident in the notorious droughts between 1984 and 1985 (Fig. 7).
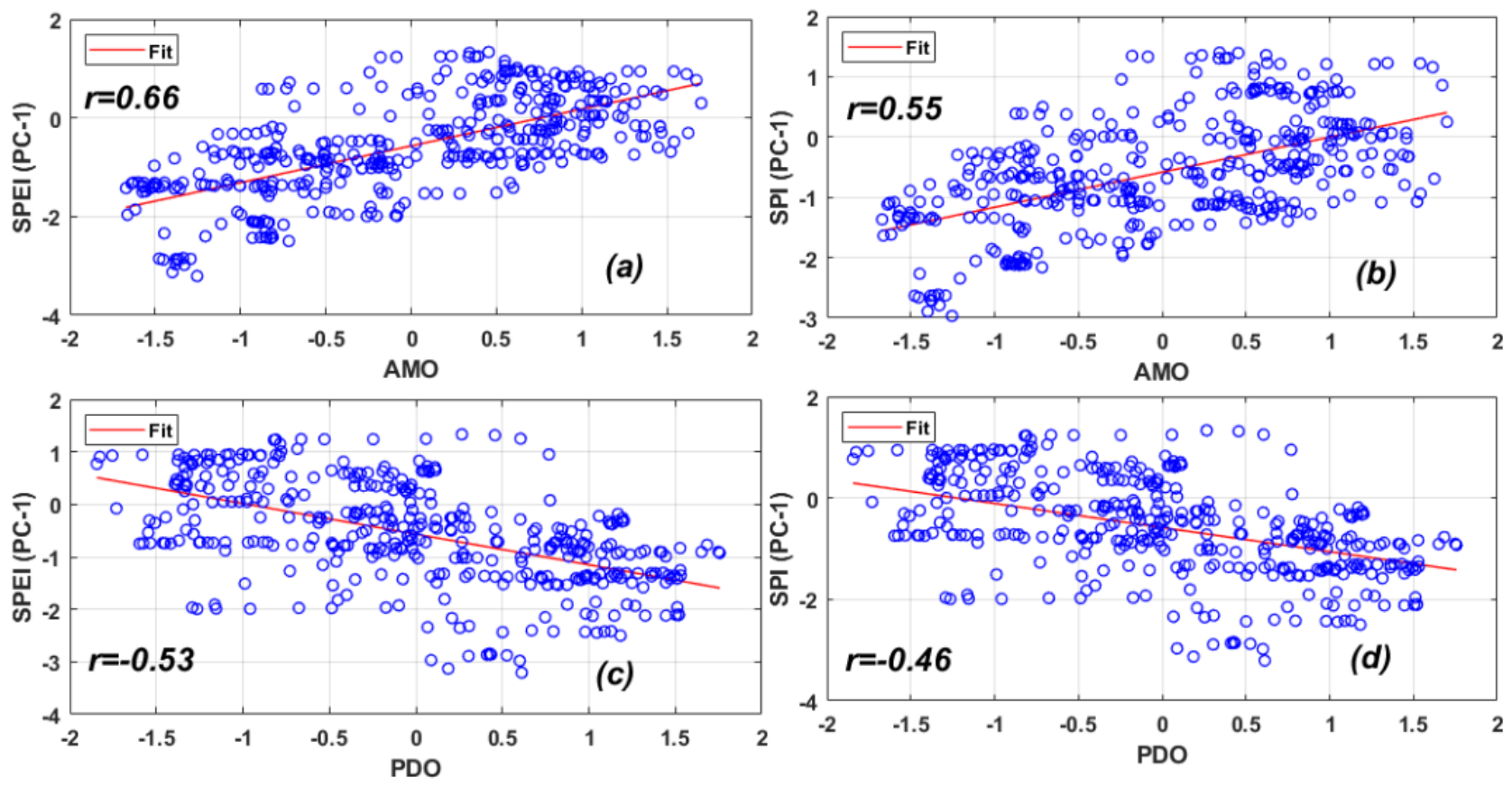

Figure 8: Leading modes of SPEI and SPI (1980 - 2014) over the Sahel and their teleconnections with low frequency climate oscillations, the (a-b) AMO and (c-d) PDO. 

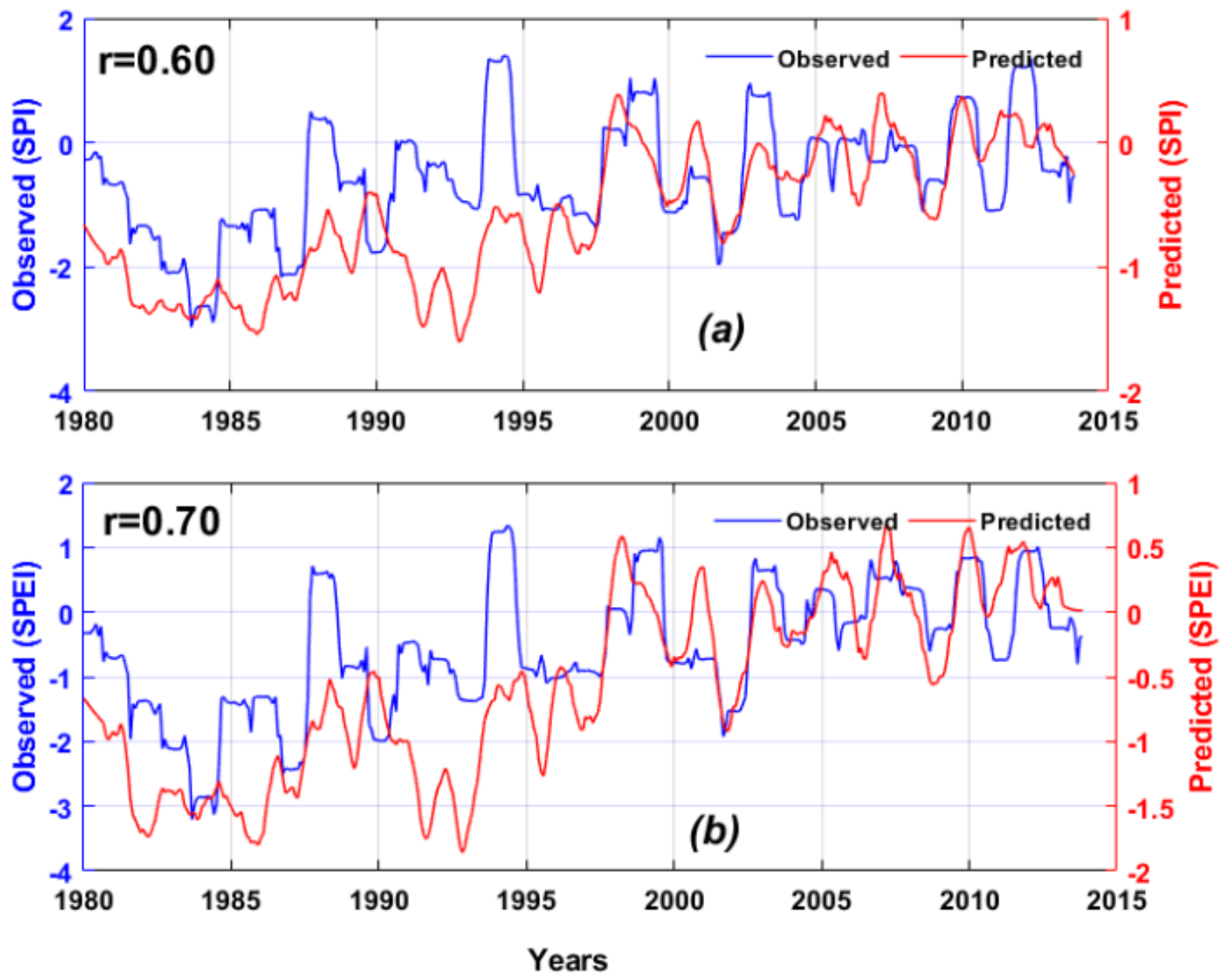

Figure 9: Modelling drought evolutions $(1980$ - 2014) over the Sahel using all seven climate teleconnections in the PLSR scheme. The temporal series of the observed and predicted drought indicators are indicated for (a) SPI and (b) SPEI.

\subsection{Drought evolutions and their teleconnections with multi-scale climate oscillations}

Preliminary assessment of a suite of climate modes and their coupled variability with the leading modes of SPEI and SPI show that low frequency oscillations such as the PDO, AMO, and AMM have significant influence on the spatio-temporal evolutions of these drought indicators in the Sahel (Fig. 8). This diagnostics confirm the interplay between interactions of low frequency oscillations with meteorological processes in the the Sahel. As summarised in Table 4, AMO shows the strongest association with SPEI and SPI $(r=0.66$ and $r=0.55)$. The PDO and AMM also show significant but modest correlations with SPEI $(r=-0.53$ and $r=0.47)$. SPI also shows moderate association with PDO $(r=-0.46)$ but less correlated with AMM $(r=0.38)$ compared to SPEI. Generally the SPEI extracts these climate teleconnections, including ENSO better than the SPI (Table 4). The Sahel is a climatic hotspot in Africa whose precipitation has been linked to 
a sequence of oceanic phenomenon and plethora of multi-scale climate teleconnections, including quasi-periodic phenomena (e.g., ENSO, sunspot activity, Quasi-Biennial Oscillation, etc.), and other low frequency oscillations (e.g., 65, 24, 50, 71). Consequently, all of the climate modes described in Section 2 where integrated in the PLSR scheme as predictors to model the temporal series of SPEI and SPI (predictands obtained from the PCA scheme) over the Sahel. So the PLSR model was formulated based on seven PLSR components, which accounted for the most variability in the climate modes. By using these climate oscillations as regression covariates to model SPEI and SPI, we found a relatively stronger correlation between predicted and observed SPEI $(r=0.70)$ unlike SPI $(r=0.60)$ (Figs. 9a and b). The PLSR coefficients, i.e., the values of $\beta$ in Eqn. 6 (Section 3) indicated AMO has the strongest predictive power. The influence of QBO, ENSO, and AMM were relatively higher than others. Be it SPEI or SPI, the temporal patterns of the predicted and observed drought indicators appear to be more associated after the 1995 period (Figs. 9a and b).

\section{Discussion}

\subsection{Understanding the complexities of droughts}

Droughts are generally the result of complex interactions amongst several factors that includes temporary decrease in water availability due to prolonged rainfall deficit, land surface processes, storage changes, and flows (e.g., 100, 94). Contemporary understanding of these interactions, especially those related to multi-scale global climate phenomena and how they contribute to the evolutions, development and propagation of drought requires functional drought metrics that capture these processes. Apparently, extreme negative precipitation anomalies in arid climates would impact on water availability and freshwater stocks. But the impacts of land surface conditions such as increased evapotranspiration (68), non-climatic factors and land surface processes, including, soil type, land cover, temperature, intensive groundwater extraction for irrigation, catchment and climate characteristics influence drought propagation (e.g., 19, 40, 99, 101). The challenge with this is that, these factors and processes do interfere with drought characteristics and propagation by affecting hydrological processes (e.g., infiltration and flow dynamics) and regulating the interactions between land surface-moisture fluxes and the atmosphere. For example, catchment stores (i.e., reservoirs, soil column, groundwater, etc.) of humid regions can create a prolonged reservoir memory in the hydrological system that could delay the propagation of drought signals or even its absence (63). But in tropical arid regions characterised by low rainfall, a rise in land surface temperature during below average temperatures could impact on drought intensity. For 
this reason, the interaction of land surface and other climatic variables have been embedded in some drought metrics like the Palmer Drought Severity Index (PDSI, 80). While the PDSI, SPI, and SPEI have been widely used along with other drought metrics, attempt by Moorhead et al. (57) to better account for actual water demand in irrigated landscapes resulted in the substitution of reference evapotranspiration in the SPEI with crop evapotranspiration. Further, it was highlighted in an earlier review of the Sahelian droughts (27) that metrics and predictive models incorporating the overarching influence of climate and human actions are essential in effective characterisation of droughts in the Sahel.

Be it variability (Figs. 4-5, Table 2) or characteristics (Figs. 6 and 7), one wonders if the relationships between SPEI and SPI as observed in this study are dynamic. Indeed, precipitation deficits are arguably the primary causes of droughts, which in turn affects other hydrological stores (e.g., groundwater). Nevertheless, strong variations in temperature, catchment characteristics, and changes in land cover states can interact with these deficits in ways that trigger dynamics in the relationships between SPEI and SPI as seen in their spatial and temporal correlations (Figs. 2a-e, Table 2). These dynamics may also explain why (i) the SPI-SPEI relationship are poor or nonexistent in some areas and (ii) the dissimilarity in predicted extents of various drought intensity for specific periods. The influence of positive feedbacks on droughts in the Sahel, for example, wet soil favoring improved rainfall from local evaporation was reported by Oguntoyinbo (76). Furthermore, droughts in the Sahel have been attributed to vegetation and land degradation, dust feedbacks and human-induced climate change (27). The feedback processes of desertification on the Sahelian climate, land use change and the complex water use mechanisms of the Sahelian vegetation during the dry season (e.g., 67, 76) could contribute to altered or dynamic land surface conditions.

On the whole, drought events across the globe are perceived as a function of changes in global climate. ENSO, for instance, is one the largest inter-annual climate phenomenon linked with extreme events such as floods and droughts on a variety of spatial scales (see, e.g., 63, 40, 83, 98, 91, 44, 106). While major drought events during the last century in North America, West Africa, and East Asia were linked to strong anomalies in tropical sea surface temperatures and other oceanic hot spots (e.g., 20), in the Australian context, the perception of droughts confirm that the factors driving drought are multi-scaled and its impacts could vary across ecosystems (98). As further highlighted by Kiem et al. (40), large scale processes such as ENSO, Interdecadal Pacific Oscillation, and Indian Ocean Dipole (IOD), are connected to droughts in Australia through direct causes such as precipitation deficits, higher temperatures, and the combined influence of precipitation and evaporation on hydrological stores (e.g., soil moisture and groundwater). Therefore, to study 
drought impacts more effectively under a rising global warming scenario, it is pertinent to rely on multi-scale drought metrics derived from a combination of water budget and biophysical variables. This is essential to enhancing our understanding of evolutionary drought patterns, that is, in terms of its variability, propagation and impacts on hydrological processes, and ecosystem services. Stressing further on this, it has been recently argued that the inclusion of multiple climate variables in drought analysis can help inform on the role of human activities (e.g., deforestation, land use change) in exacerbating drought events (63). This could lead to optimizing predictive models that seeks to account for the impacts of natural variability and anthropogenic climate change on seasonal drought characteristics and it evolutions (40).

\subsection{On the need to optimize drought indicators}

The use of normalised rainfall deviations in drought assessment in the Sahel has been challenged by some studies because the spatial aggregation of rainfall departures hides the underlying key local variation and drivers, and that the averaging period restricts drought characterisation and interpretation (e.g., 62, 2). It is on this note that drought indicators that utilises multiple climate variables have been advocated in recent times (e.g., 62, 1, 29). The argument around this emphasises the deficiency of drought indicators based on a single climate variable (rainfall) because it lacks the capacity to sufficiently describe key drought metrics and characteristics such as onset, duration, severity, frequency and intensity (e.g., 66, 35). Even more recently, the limitations associated with the use of drought metrics based on rainfall alone has been re-echoed (69) whilst portraying the effectiveness of SPEI in characterizing drought severity and frequency under increase global warming (93). Apparently, the SPEI and SPI show marked differences in terms of spatio-temporal variability (Fig. 2d) and distribution over different time scales. On the one hand, the wider spread of strong positive correlations (SPEI vs SPI) during the $1961-1990$ period (Figs. 3 and 5) as opposed to other climatological periods (Fig. 2b-c and e) raises concerns on the need for drought metrics that capture land surface conditions and their interactions more effectively in the Sahel. For instance, topography, soil characteristics, and vegetation can influence drought intensity and characteristics through their interactions under extreme temperature and precipitation anomalies. On the other hand, this could also suggest evapotranspiration rates or both rainfall and temperature are important climate variables to understanding the variability or intensity of drought events in the semi-arid Sahel. For example, SPEI indicated that the notorious drought of the early 1980s was more extreme in central Niger (between 1984/1985) unlike SPI (SPEI-1, Fig. 5). The argument that the multi-scalar nature of SPEI enhances its utility in the characterization of various drought 
intensities (104) is indirectly supported by the fact that sugarcane production in semi-arid region of Brazil was significantly influenced by both temperature and rainfall (22).

It is true that indicators and metrics are at the center of numerous assessments, including those used to designate human development, environmental sustainability and performance. The same goes for drought intensity and characteristics, unmitigated impacts of climate change, and impact assessment from drought. Hence, the innovative applications of these drought indicators in diagnostic studies are essential. In particular, the use of such metrics to further explore the impacts of climate variability drivers on drought events could be fundamental and of course the genesis to improving regional climate predictions and mitigation strategies that will foster complementary interventions. A comparative assessment between SPEI and SPI during different climatological and historical windows confirm that strong land-atmosphere interactions slightly interfere with drought intensities and the propagation of droughts in the Sahel. Further, the relationship between SPEI and SPI and their predicted extents of various drought intensities apparently alludes to this, giving the notion that evapotranspiration dynamics in the region are significant triggers of hydrological conditions other than rainfall. So, drought indicators based on biophysical variables (e.g., land surface temperature, vegetation condition index) are important metrics to support the accounting process that aid the understanding of drought impacts and its cascading effects. For instance, given the devastating impacts of water deficits on crop production (e.g., 61, 3, 84), agricultural drought monitoring and characterisation can be optimised by integrating evapotranspiration with other water budget indicators. The argument along this lines emphasize that evapotranspiration is a key component of agricultural water budget, hence the suitability of SPEI to assess agricultural drought for summer crops in Texas High Plains (57). Considering the impacts of existing chains of climate teleconnections around the globe, land cover changes, and local feedbacks on meteorological processes and drought propagation and characteristics, there is need for the hydrologic community to move towards multiple metrics to provide a more realistic profile of droughts and their drivers.

\subsection{Coupled variability of multi-scale climate modes and their influence on extreme events}

Some earlier studies in the Sahel region identified the coupled relationship of several teleconnections, e.g., ENSO and IOD, AMO, with rainfall (e.g., 63, 24, 78, 79). The influence of these climate modes, especially IOD and ENSO on rainfall variability in East and other African sub-region tend to be widely received (e.g., 32, 4, 97). However, due to the multivariate non-parametric forecast scheme in this study, which identifies AMO as the leading low frequency climate signal in the West African Sahel, the perceived impacts of IOD on the droughts of the early 1980s in the Sahel and 
in general, its role in the West African climatology as argued in previous reports $(7,31)$ would require further experiment and clarity. This is because precipitation extremes in West Africa are usually associated with circulation features and climate teleconnection indices of the Pacific and the Atlantic, land-ocean contrast amongst others (see, e.g., 24, 72). The controversy surrounding the role of IOD on rainfall anomalies in the Sahel has been highlighted in some case-specific studies mentioned in Nicholson (71). Although the existence of IOD-induced land water storage in West Africa was found to be complimentary, its impacts on surface hydrology still appears to be cloudy (64). Arguably, the influence of teleconnections on rainfall might not directly be the same as its influence on surface hydrology because of the intrinsic response of freshwater in some regions to indices of oceanic variability. Hence, global climate simulations integrating IOD-like SST anomalies are important consideration in future studies to clarify the role of IOD on the Sahelian climate. That ENSO is one of the key processes of inter-annual variability and a well known teleconnection with significant influence on hydro-meteorological processes in several regions around the world is less debated. But the links (i.e., observed linear relationship) between drought metrics over the Sahel with AMO, AMM, and PDO (Fig. 5 and Table 4) are further evidence that confirm the roles of low frequency oscillations on the climatology of the region. Be it at basin or regional-scale, some past diagnostic studies have also alluded to the influence of these low frequency climate patterns in the hydro-climatic extremes of the West African sub-region (e.g., 64, 63, 24, 78). In addition to the dominant influence of AMO as the strongest predictor of extreme events in the Sahel, outputs from our PLSR model also highlights the interactions of AMM, ENSO and QBO with drought patterns, and re-emphasizes these teleconnections as important physical mechanisms that drives meteorological processes and drought evolutions. These results suggest the Sahel is characterised by quasi-biennial, multi-decadal, and inter-annual climate oscillations. It also indicate that temporal drought evolutions can be predicted by the synthesis of these global multi-scale climate elements. The mechanistic understanding of this multi-scale climate influence nonetheless, and how they drive precipitation extremes in the Sahel are interesting new research directions for the region.

\section{Conclusion}

The continued influence of atmospheric circulation features, warming of the tropical oceans, and indices of climate variability on hydro-meteorological processes is increasing and gaining attention. The Sahel is a popular hot spot of extreme events and environmental degradation and has been the center of several eco-hydrological and hydro-meteorological studies, with considerable reports in the last two decades focused on the impact of oceanic phenomena on precipitation patterns. While the 
debate on the mechanisms behind the Sahelian drought is still ongoing, the evolutionary patterns of historical drought episodes in the region and their teleconnections to low frequency climate oscillations is undocumented. While more diagnostic studies are warranted to increase drought preparedness and aid the optimization of existing templates on risk mitigation in drought-prone areas, the other non-trivial challenge is identifying drought metrics that captures more effectively the slow but dynamic large-scale climate processes. Indeed, indicators and metrics are at the center of numerous assessments, including those used to designate human development and environmental performance. The need for suitable metrics to explore the impacts of climate variability drivers on drought intensity and characteristics was therefore one of the key motivations for this study. The main aim of this study therefore was to assess evolutionary drought patterns over the West African Sahel (1901-2014) and their teleconnections with low frequency climate oscillations during the last three decades by integrating drought indicators and a suite of global climate modes as predictors in a multivariate framework. The results are summarised as follows;

(i) The spatio-temporal distribution and variability of SPEI and SPI over the West African Sahel in four different climatological periods during the $1901-2015$ period are generally consistent and strongly correlated around the central Sahel, howbeit with dissimilarity (in terms of variability and characteristics) in some regions. Although precipitation deficits are the primary causes of droughts, strong variations in temperature, catchment characteristics, and changes in land cover states could interact with these deficits in ways that trigger dynamics in SPEI leading to the poor SPI-SPEI relationship.

(ii) The worst drought during the 20th century occurred between 1982 and 1985, affecting more than $90 \%$ of the region during the 1984 - 1985 period while the 1950 s was the wettest on record. Apart from this period, affected drought areas fluctuated between $70 \%$ at the start of the century and about $60 \%$ in the mid 1970s. Overall, the 1980s was a terrific drought period with extreme drought affecting about $85 \%$ of the region between 1987 and 1988. But the period between 2005 and 2015 show that drought episodes and their intensities have diminished and varied less over the Sahel. However, the Sahel is still not as wet as the 1950 - 1960 period.

(iii) Generally, SPEI and SPI also compare rather well in their characterisation of various drought intensities and estimation of affected areas. However, to study drought impacts more effectively under a rising global warming scenario, it is pertinent to rely on multi-scalar metrics derived from a combined water budget and biophysical variables. While this is essential to 
improve our knowledge of drought characteristics (e.g., onset, duration, and magnitude), the slight differences in predicted drought extents in some areas of the Sahel by both indicators emphasize the need for functional drought metrics that capture the complex interactions of land surface processes with catchment and climate characteristics that influence drought propagation. Moreover, the ability of SPEI to extract climate teleconnections more than SPI is important for climate risk assessments and optimization of climate models. The inclusion of human-induced factors, biophysical and climatic variables derived from remote sensing data (e.g., vegetation-based indicators, satellite precipitation, etc.) in numerical models can help improve drought characterisation and prediction.

(iv) Preliminary assessment of a suite of climate modes and their coupled variability with the leading modes of SPEI and SPI show that low frequency oscillations such as the PDO, AMO, and AMM have significant influence on the spatio-temporal evolutions of these drought indicators in the Sahel. In addition to the dominant influence of AMO as one of the strongest drivers of drought events in the Sahel, outputs from the partial least square regression model also highlights the interactions of AMM, ENSO and QBO with drought patterns. This outcome re-emphasizes these climate teleconnections as important physical mechanisms that drive meteorological processes and drought evolutions, and suggest the Sahelian hydro-climatology is characterised by quasi-biennial, multi-decadal, and inter-annual climate oscillations. Given that these relationships are linear, there could be other climate modes (or a combination of climate modes) that are also indirectly (non-linear) associated with droughts in the Sahel. 
551

552

\section{Acknowledgments}

The authors are grateful to National Oceanic and Atmospheric Administration for all the data used in this study. A. Getirana was funded by NASA's Applied Sciences Program - SERVIR (NNH15ZDA001N-SERVIR). The constructive comments of three anonymous reviewers and the Editor helped in improving the content and quality of this article. 


\section{References}

[1] AghaKouchak, A. (2015). A multivariate approach for persistence-based drought prediction: Application to the 2010-2011 East Africa drought. Journal of Hydrology, 526:127 - 135. doi:10.1016/j.jhydrol.2014.09.063.

[2] Agnew, C. and Chappell, A. (1999). Drought in the sahel. GeoJournal, 48(4):299-311. doi:10.1023/A:1007059403077.

[3] Agutu, N., Awange, J., Zerihun, A., Ndehedehe, C., Kuhn, M., and Fukuda, Y. (2017). Assessing multi-satellite remote sensing, reanalysis, and land surface models' products in characterizing agricultural drought in East Africa. Remote Sensing of Environment, 194(0):287-302. doi:10.1016/j.rse.2017.03.041.

[4] Andam-Akorful, S., Ferreira, V., Ndehedehe, C. E., and Quaye-Ballard, J. (2017). An investigation into the freshwater variability in West Africa during 1979 - 2010. International Journal of Climatology, 37(S1):333-349. doi:10.1002/joc.5006.

[5] Anyah, R., Forootan, E., Awange, J., and Khaki, M. (2018). Understanding linkages between global climate indices and terrestrial water storage changes over africa using GRACE products. Science of The Total Environment, 635:1405 - 1416. doi:10.1016/j.scitotenv.2018.04.159.

[6] Asong, Z. E., Wheater, H. S., Bonsal, B., Razavi, S., and Kurkute, S. (2018). Historical drought patterns over Canada and their teleconnections with large-scale climate signals. Hydrology and Earth System Sciences, 22(6):3105-3124. doi:10.5194/hess-22-3105-2018.

[7] Bader, J. and Latif, M. (2011). The 1983 drought in the West Sahel: A case study. Climate Dynamics, 36(3-4):463-472. doi:10.1007/s00382-009-0700-y.

[8] Bahaga, T. K., Fink, A. H., and Knippertz, P. (2019). Revisiting interannual to decadal teleconnections influencing seasonal rainfall in the Greater Horn of Africa during the 20th century. International Journal of Climatology.

[9] Bazrafshan, J., Hejabi, S., and Rahimi, J. (2014). Drought monitoring using the multivariate standardized precipitation index (MSPI). Water Resources Mangagement, 28:1045-1060. doi:10.1007/s11269-014-0533-2.

[10] Becker, A., Finger, P., Meyer-Christoffer, A., Rudolf, B., Schamm, K., Schneider, U., and Ziese, M. (2013). A description of the global land-surface precipitation data products of the 
Global Precipitation Climatology Centre with sample applications including centennial (trend) analysis from 1901 to present. Earth System Science Data, 5(1):71-99. doi:10.5194/essd-5-712013.

[11] Boening, C., Willis, J. K., Landerer, F. W., Nerem, R. S., and Fasullo, J. (2012). The 2011 La Niña: So strong, the oceans fell. Geophysical Research Letters, 39(19):L19602. doi:10.1029/2012GL053055.

[12] Bonaccorso, B., Bordi, I., Cancelliere, A., Rossi, G., and Sutera, A. (2003). Spatial variability of drought: An analysis of the SPI in Sicily. Water Resources Management, 17(4):273-296. doi:10.1023/A:1024716530289.

[13] Brown, C. and Lall, U. (2006). Water and economic development: The role of variability and a framework for resilience. Natural Resources Forum, 30(4):306-317.

[14] Brown, C., Meeks, R., Hunu, K., and Yu, W. (2011). Hydroclimate risk to economic growth in sub-Saharan Africa. Climatic Change, 106(4):621-647. doi:10.1007/s10584-010-9956-9.

[15] Cao, G., Han, D., and Song, X. (2014). Evaluating actual evapotranspiration and impacts of groundwater storage change in the North China Plain. Hydrological Processes, 28(4):1797-1808. doi:10.1002/hyp.9732.

[16] Cenacchi, N. (2014). Drought risk reduction in agriculture: A review of adaptive strategies in East Africa and the Indo-Gangetic plain of South Asia. International Food Policy Research Institute (IFPRI), discussion Paper 1372. Retrieved from:http://ebrary.ifpri.org/cdm/ref/collection/p15738coll2/id/128277 23 September, 2017.

[17] Chen, H., Sun, Y., Gao, J., Hu, Y., and Yin, B. (2018). Solving partial least squares regression via manifold optimization approaches. IEEE Transactions on Neural Networks and Learning Systems, pages 1-13. doi:10.1109/TNNLS.2018.2844866.

[18] Chen, T., de Jeu, R., Liu, Y., van der Werf, G., and Dolman, A. (2014). Using satellite based soil moisture to quantify the water driven variability in NDVI: A case study over mainland Australia. Remote Sensing of Environment, 140:330 - 338. doi:10.1016/j.rse.2013.08.022.

[19] Cook, B. I., Mankin, J. S., and Anchukaitis, K. J. (2018). Climate change and drought: From past to future. Current Climate Change Reports, 4(2):164-179. doi:10.1007/s40641-018-0093-2. 
[20] Dai, A. (2011). Drought under global warming: a review. Wiley Interdisciplinary Reviews: Climate Change, 2(1):45-65.

[21] de Jong, S. (1993). SIMPLS: An alternative approach to partial least squares regression. Chemometrics and Intelligent Laboratory Systems, 18(3):251-263. doi:10.1016/01697439(93)85002-x.

[22] de Medeiros Silva, W. K., de Freitas, G. P., Coelho Junior, L. M., de Almeida Pinto, P. A. L., and Abrahão, R. (2019). Effects of climate change on sugarcane production in the state of Paraíba (Brazil): a panel data approach (1990-2015). Climatic Change, 154(1):195-209. doi:10.1007/s10584-019-02424-7.

[23] Dezfuli, A. K. and Nicholson, S. E. (2013). The relationship of rainfall variability in Western Equatorial Africa to the tropical oceans and atmospheric circulation. part ii: The boreal autumn. Journal of Climate, 26(1):66-84. doi:10.1175/JCLI-D-11-00686.1.

[24] Diatta, S. and Fink, A. H. (2014). Statistical relationship between remote climate indices and West African monsoon variability. International Journal of Climatology, 34(12):3348-3367. doi:0.1002/joc.3912.

[25] Diaz, H. F., Hoerling, M. P., and Eischeid, J. K. (2001). Enso variability, teleconnections and climate change. International Journal of Climatology, 21(15):1845-1862. doi:10.1002/joc.631.

[26] Enfield, D. and Mestas-Nuñez, A. (1999). Multiscale variabilities in global sea surface temperatures and their relationships with tropospheric climate patterns. Journal of Climate, 12(9):27192733. doi:10.1175/1520-0442(1999)012<2719:MVIGSS>2.0.CO;2.

[27] Epule, E. T., Peng, C., Lepage, L., and Chen, Z. (2014). The causes, effects and challenges of sahelian droughts: a critical review. Regional Environmental Change, 14(1):145-156. doi:10.1007/s10113-013-0473-z.

[28] FAO (2016). Climate change and food security: risks and responses. Food and Agricultural Organisation of the United Nations. Retrieved from http://www.fao.org/3/a-i5188e.pdf 20 September 2016.

[29] Farahmand, A. and AghaKouchak, A. (2015). A generalized framework for deriving nonparametric standardized drought indicators. Advances in Water Resources, (76):140-145. doi:/10.1016/j.advwatres.2014.11.012. 
[30] Ferreira, V., Montecino, H., Ndehedehe, C., Heck, B., Gong, Z., Westerhaus, M., and de Freitas, S. (2018). Space-based observations of crustal deflections for drought characterization in brazil. Science of The Total Environment, 644:256-273. doi:10.1016/j.scitotenv.2018.06.277.

[31] Giannini, A., Saravanan, R., and Chang, P. (2003). Oceanic forcing of Sahel rainfall on interannual to decadal time scales. Science, 302(5647):1027-1030. doi:10.1126/science.1089357.

[32] Gizaw, M. S. and Gan, T. Y. (2017). Impact of climate change and El Niño episodes on droughts in sub-Saharan Africa. Climate Dynamics, 49(1):665-682. doi:10.1007/s00382-016$3366-2$.

[33] Guan, K., Wood, E. F., Medvigy, D., Kimball, J., Pan, M., Caylor, K. K., Sheffield, J., Xu, X., and Jones, M. O. (2014). Terrestrial hydrological controls on land surface phenology of African savannas and woodlands. Journal of Geophysical Research: Biogeosciences, 119(8):1652-1669. doi:10.1002/2013JG002572.

[34] Hall, J. W., Grey, D., Garrick, D., Fung, F., Brown, C., Dadson, S. J., and Sadoff, C. W. (2014). Coping with the curse of freshwater variability. Science, 346(6208):429-430. doi:10.1126/science.1257890.

[35] Hao, Z. and AghaKouchak, A. (2014). A nonparametric multivariate multi-index drought monitoring framework. Journal of Hydrometeorology, 15(1):89-101. doi:10.1175/JHM-D-120160.1.

[36] Huber, S., Fensholt, R., and Rasmussen, K. (2011). Water availability as the driver of vegetation dynamics in the African Sahel from 1982 to 2007. Global and Planetary Change, 76(3â€"4):186 - 195. doi:10.1016/j.gloplacha.2011.01.006.

[37] Ivits, E., Horion, S., Fensholt, R., and Cherlet, M. (2014). Drought footprint on European ecosystems between 1999 and 2010 assessed by remotely sensed vegetation phenology and productivity. Global Change Biology, 20(2):581-593. doi:10.1111/gcb.12393.

[38] Jolliffe, I. T. (2002). Principal component analysis (second edition). Springer Series in Statistics. Springer, New York.

[39] Karl, T. R. and Koscielny, A. J. (1982). Drought in the United States: 1895-1981. Journal of Climatology, 2(4):313-329. doi:10.1002/joc.3370020402. 
[40] Kiem, A. S., Johnson, F., Westra, S., van Dijk, A., Evans, J. P., O'Donnell, A., Rouillard, A., Barr, C., Tyler, J., Thyer, M., Jakob, D., Woldemeskel, F., Sivakumar, B., and Mehrotra, R. (2016). Natural hazards in Australia: droughts. Climatic Change, 139(1):3754. doi:10.1007/s10584-016-1798-7.

[41] Knauer, K., Gessner, U., Dech, S., and Kuenzer, C. (2014). Remote sensing of vegetation dynamics in West Africa. International Journal of Remote Sensing, 35(17):6357-6396. doi:10.1080/01431161.2014.954062.

[42] Koster, R. D., Dirmeyer, P. A., Guo, Z., Bonan, G., Chan, E., Cox, P., Gordon, C. T., Kanae, S., Kowalczyk, E., Lawrence, D., Liu, P., Lu, C.-H., Malyshev, S., McAvaney, B., Mitchell, K., Mocko, D., Oki, T., Oleson, K., Pitman, A., Sud, Y. C., Taylor, C. M., Verseghy, D., Vasic, R., Xue, Y., and Yamada, T. (2004). Regions of strong coupling between soil moisture and precipitation. Science, 305(5687):1138-1140. doi:10.1126/science.1100217.

[43] Kubiak-Wójcicka, K. and Bąk, B. (2018). Monitoring of meteorological and hydrological droughts in the Vistula basin (Poland). Environmental Monitoring and Assessment, 190(11):691. doi:10.1007/s10661-018-7058-8.

[44] Kumar, K. N., Rajeevan, M., Pai, D., Srivastava, A., and Preethi, B. (2013). On the observed variability of monsoon droughts over India. Weather and Climate Extremes, 1:42 - 50 . doi:10.1016/j.wace.2013.07.006.

[45] Kurnik, B., Kajfež-Bogataj, L., and Horion, S. (2015). An assessment of actual evapotranspiration and soil water deficit in agricultural regions in Europe. International Journal of Climatology, 35(9):2451-2471. doi:10.1002/joc.4154.

[46] Latif, M. and Barnett, T. (1996). Decadal climate variability over the North Pacific and North America: Dynamics and predictability. Journal of Climate, 9(10):2407-2423. doi:10.1175/15200442(1996)009<2407:DCVOTN >2.0.CO;2.

[47] Lewis-Beck, M., Bryman, A., and Futing, T. (2003). Encyclopedia of social sciences research methods. Thousand Oaks (CA): Sage, pages accessed from https://www.utdallas.edu/ herve/Abdi-PLS-pretty.pdf on 4th January 2019.

[48] L'Hôte, Y., Mahé, G., Somé, B., and Triboulet, J. P. (2002). Analysis of a Sahelian annual rainfall index from 1896 to 2000; the drought continues. Hydrological Sciences Journal, 47(4):563572. doi:10.1080/02626660209492960. 
[49] Mahe, G., Lienou, G., Descroix, L., Bamba, F., Paturel, J. E., Laraque, A., Meddi, M., Habaieb, H., Adeaga, O., Dieulin, C., Chahnez Kotti, F., and Khomsi, K. (2013). The rivers of Africa: witness of climate change and human impact on the environment. Hydrological Processes, $27(15): 2105-2114$.

[50] Martin, E. R. and Thorncroft, C. D. (2014). The impact of AMO on the West African monsoon annual cycle. Quarterly Journal of the Royal Meteorological Society, 140:31-46. doi:10.1002/qj.2107.

[51] McKee, T. B., Doeskin, N. J., and Kieist, J. (1993). The relationship of drought frequency and duration to time scales. Conference on Applied Climatology, American Meteorological Society,Boston, Massachusetts, pages 179-184. Retrieved from:www.ccc.atmos.colostate.edu/relationshipofdroughtfrequency.pdf. Accessed 27 June, 2014.

[52] Melo, D. D. C. D., Scanlon, B. R., Zhang, Z., Wendland, E., and Yin, L. (2016). Reservoir storage and hydrologic responses to droughts in the parana river basin, south-eastern Brazil. Hydrology and Earth System Sciences, 20(11):4673-4688. doi:10.5194/hess-20-4673-2016.

[53] Mishra, A. K. and Singh, V. P. (2010). A review of drought concepts. Journal of Hydrology, 391:202-216. doi:10.1016/j.jhydrol.2010.07.012.

[54] Mohino, E., Janicot, S., and Bader, J. (2011a). Sahel rainfall and decadal to multi-decadal sea surface temperature variability. Climate Dynamics, 37:419-440. doi:10.1007/s00382-010-0867-2.

[55] Mohino, E., RodrÃguez-Fonseca, B., Losada, T., Gervois, S., Janicot, S., Bader, J., Ruti, P., and Chauvin, F. (2011b). Changes in the interannual SST-forced signals on West African rainfall. AGCM intercomparison. Climate Dynamics, 37(9-10):1707-1725. doi:10.1007/s00382011-1093-2.

[56] Montazerolghaem, M., Vervoort, W., Minasny, B., and McBratney, A. (2016). Long-term variability of the leading seasonal modes of rainfall in south-eastern Australia. Weather and Climate Extremes, 13:1 - 14. doi:10.1016/j.wace.2016.04.001.

[57] Moorhead, J. E., Gowda, P. H., Singh, V. P., Porter, D. O., Marek, T. H., Howell, T. A., and Stewart, B. (2015). Identifying and evaluating a suitable index for agricultural drought monitoring in the Texas High Plains. JAWRA Journal of the American Water Resources Association, 51(3):807-820. doi:10.1111/jawr.12275. 
[58] Mpelasoka, F., Awange, J. L., and Zerihun, A. (2018). Influence of coupled ocean-atmosphere phenomena on the greater horn of africa droughts and their implications. Science of The Total Environment, 610-611:691 - 702. doi:10.1016/j.scitotenv.2017.08.109.

[59] Ndehedehe, C., Awange, J., Agutu, N., Kuhn, M., and Heck, B. (2016a). Understanding changes in terrestrial water storage over West Africa between 2002 and 2014. Advances in Water Resources, 88:211-230. doi:10.1016/j.advwatres.2015.12.009.

[60] Ndehedehe, C. E. (2019). The water resources of tropical West Africa: propblems, progress and prospect. Acta Geophysica, 67(2):621-649. https://doi.org/10.1007/s11600-019-00260-y.

[61] Ndehedehe, C. E., Agutu, N. O., and Okwuashi, O. (2018a). Is terrestrial water storage a useful indicator in assessing the impacts of climate variability on crop yield in semi-arid ecosystems? Ecological Indicators, 88C:51-62. doi:10.1016/j.ecolind.2018.01.026.

[62] Ndehedehe, C. E., Agutu, N. O., Okwuashi, O. H., and Ferreira, V. G. (2016b). Spatio-temporal variability of droughts and terrestrial water storage over Lake Chad Basin using independent component analysis. Journal of Hydrology, 540:106-128. doi:10.1016/j.jhydrol.2016.05.068.

[63] Ndehedehe, C. E., Anyah, R. O., Alsdorf, D., Agutu, N. O., and Ferreira, V. G. (2019a). Modelling the impacts of global multi-scale climatic drivers on hydro-climatic extremes (1901-2014) over the Congo basin. Science of The Total Environment, 651:1569 - 1587. doi:10.1016/j.scitotenv.2018.09.203.

[64] Ndehedehe, C. E., Awange, J., Kuhn, M., Agutu, N., and Fukuda, Y. (2017). Climate teleconnections influence on West Africa's terrestrial water storage. Hydrological Processes, 31(18):32063224. doi: 10.1002/hyp.11237.

[65] Ndehedehe, C. E., Awange, J. L., Agutu, N. O., and Okwuashi, O. (2018b). Changes in hydrometeorological conditions over tropical West Africa $(1980$ - 2015) and links to global climate. Global and Planetary Change, 162:321-341. doi:10.1016/j.gloplacha.2018.01.020.

[66] Ndehedehe, C. E., Awange, J. L., Corner, R., Kuhn, M., and Okwuashi, O. (2016c). On the potentials of multiple climate variables in assessing the spatio-temporal characteristics of hydrological droughts over the Volta Basin. Science of the Total Environment, 557-558:819-837. doi:10.1016/j.scitotenv.2016.03.004. 
[67] Ndehedehe, C. E., Ferreira, V. G., and Agutu, N. O. (2019b). Hydrological controls on surface vegetation dynamics over West and Central Africa. Ecological Indicators, 103:494 - 508. doi:10.1016/j.ecolind.2019.04.032.

[68] Ndehedehe, C. E., Okwuashi, O., Ferreira, V. G., and Agutu, N. O. (2018c). Exploring evapotranspiration dynamics over sub-sahara africa (2000 - 2014). Environmental Monitoring and Assessment, 190(7):400. doi:10.1007/s10661-018-6780-6.

[69] Nguvava, M., Abiodun, B. J., and Otieno, F. (2019). Projecting drought characteristics over East African basins at specific global warming levels. Atmospheric Research, 228:41 54. doi:10.1016/j.atmosres.2019.05.008.

[70] Nicholson, S. (2005). On the question of the "recovery" of the rains in the West African Sahel. Journal of Arid Environments, 63(3):615-641. doi:10.1016/j.jaridenv.2005.03.004.

[71] Nicholson, S. (2013). The West African Sahel: a review of recent studies on the rainfall regime and its interannual variability. ISRN Meteorology, 2013(453521):1-32. doi:10.1155/2013/453521.

[72] Nicholson, S. and Grist, J. (2001). A conceptual model for understanding rainfall variability in the West African Sahel on interannual and interdecadal timescales. International Journal Of Climatology, 21:1733-1757. doi:10.1002/joc.648.

[73] Nicholson, S. E. (2014). Spatial teleconnections in African rainfall: A comparison of 19th and 20th century patterns. Holocene, 24(12):1840-1848. doi:10.1177/0959683614551230.

[74] Nicholson, S. E. and Dezfuli, A. K. (2013). The relationship of rainfall variability in western equatorial Africa to the tropical oceans and atmospheric circulation. Part I: The Boreal Spring. Journal of Climate, 26(1):45-65. doi:10.1175/Jcli-D-11-00653.1.

[75] Nicholson, S. E., Funk, C., and Fink, A. H. (2018). Rainfall over the African continent from the 19th through the 21st century. Global and Planetary Change, 165:114 - 127. doi:10.1016/j.gloplacha.2017.12.014.

[76] Oguntoyinbo, J. S. (1986). Drought prediction. Climatic Change, 9(1):79-90. doi:10.1007/BF00140527.

[77] Okewu, E., Misra, S., Sanz, L. F., Ayeni, F., Mbarika, V., and Damaševičius, R. (2019). Deep Neural Networks for curbing climate change-induced farmers-herdsmen clashes in a sustainable social inclusion initiative. Problems Of Sustainable Development, 14(2):143-155. 
[78] Okonkwo, C. (2014). An advanced review of the relationships between Sahel precipitation and climate indices: A wavelet approach. International Journal of Atmospheric Sciences, 2014:11. doi:10.1155/2014/759067.

[79] Paeth, H., Fink, A., Pohle, S., Keis, F., Machel, H., and Samimi, C. (2012). Meteorological characteristics and potential causes of the 2007 flood in sub-Saharan Africa. International Journal of Climatology, 31:1908-1926. doi:10.1002/Joc.2199.

[80] Palmer, W. (1965). Meteorological drought. Weather. Bureau, U.S. Department of Commerce, Washington,. Research Paper 45. D. C. (58 pp).

[81] Pérez-Escamilla, R., Gubert, M. B., Rogers, B., and Hromi-Fiedler, A. (2017). Food security measurement and governance: Assessment of the usefulness of diverse food insecurity indicators for policy makers. Global Food Security. doi:10.1016/j.gfs.2017.06.003.

[82] Ramarohetra, J., Sultan, B., Baron, C., Gaiser, T., and Gosset, M. (2013). How satellite rainfall estimate errors may impact rainfed cereal yield simulation in West Africa. Agricultural and Forest Meteorology, 180:118 - 131. doi:10.1016/j.agrformet.2013.05.010.

[83] Rippey, B. R. (2015). The U.S. drought of 2012. Weather and Climate Extremes, 10(Part A):57 - 64. doi:10.1016/j.wace.2015.10.004.

[84] Roudier, P., Sultan, B., Quirion, P., and Berg, A. (2011). The impact of future climate change on West African crop yields: What does the recent literature say? Global Environmental Change, 21:1073-1083. doi:10.1016/j.gloenvcha.2011.04.007.

[85] Sanogo, S., Fink, A. H., Omotosho, J. A., Ba, A., Redl, R., and Ermert, V. (2015). Spatiotemporal characteristics of the recent rainfall recovery in West Africa. International Journal of Climatology, 35(15):4589-4605. doi:10.1002/joc.4309.

[86] Santos, J. a. F., Pulido-Calvo, I., and Portela, M. M. (2010). Spatial and temporal variability of droughts in Portugal. Water Resources Research, 46(3):W03503. doi:10.1029/2009WR008071.

[87] Savitzky, A. and Golay, M. J. E. (1964). Soothing and differentiation of data by simplified least squares procedures. Analytical Chemistry, 36(8):1627-1639.

[88] Schneider, U., Becker, A., Finger, P., Meyer-Christoffer, A., Ziese, M., and Rudolf, B. (2014). GPCC's new land surface precipitation climatology based on quality-controlled in situ data and 
its role in quantifying the global water cycle. Theoretical and Applied Climatology, 115(1-2):1540. doi:10.1007/s00704-013-0860-x.

[89] Schroth, G., Läderach, P., Martinez-Valle, A. I., Bunn, C., and Jassogn, L. (2016). Vulnerability to climate change of cocoa in West Africa: Patterns, opportunities and limits to adaptation. Science of the Total Environment, 556:231-241. doi:10.1016/j.scitotenv.2016.03.024.

[90] Seghieri, J., Carreau, J., Boulain, N., De Rosnay, P., Arjounin, M., and Timouk, F. (2012). Is water availability really the main environmental factor controlling the phenology of woody vegetation in the central Sahel ? Plant Ecology, 213(5):861-870. doi:10.1007/s11258-012-0048-y.

[91] Sheffield, J. and Wood, E. F. (2008). Global trends and variability in soil moisture and drought characteristics, 1950-2000, from observation-driven simulations of the terrestrial hydrologic cycle. Journal of Climate, 21(3):432-458. doi:10.1175/2007JCLI1822.1.

[92] Shiferaw, B., Tesfaye, K., Kassie, M., Abate, T., Prasanna, B., and Menkir, A. (2014). Managing vulnerability to drought and enhancing livelihood resilience in sub-Saharan Africa:technological, institutional and policy options. Weather and Climate Extremes, 3(0):67 79. doi:10.1016/j.wace.2014.04.004.

[93] Shiru, M. S., Shahid, S., Chung, E.-S., and Alias, N. (2019). Changing characteristics of meteorological droughts in Nigeria during 1901-2010. Atmospheric Research, 223:60 - 73. doi:10.1016/j.atmosres.2019.03.010.

[94] Spinoni, J., Naumann, G., Carrao, H., Barbosa, P., and Vogt, J. (2014). World drought frequency, duration, and severity for 1951-2010. International Journal of Climatology, 34(8):27922804. doi:10.1002/joc.3875.

[95] Sun, Q., Miao, C., Duan, Q., Ashouri, H., Sorooshian, S., and Hsu, K.-L. (2018). A review of global precipitation data sets: Data sources, estimation, and intercomparisons. Reviews of Geophysics, 56(1):79-107. doi:10.1002/2017RG000574.

[96] Tadesse, T., Senay, G. B., Berhan, G., Regassa, T., and Beyene, S. (2015). Evaluating a satellite-based seasonal evapotranspiration product and identifying its relationship with other satellite-derived products and crop yield: A case study for Ethiopia. International Journal of Applied Earth Observation and Geoinformation, 40(Supplement C):39 - 54 . doi:10.1016/j.jag.2015.03.006. 
[97] Ujeneza, E. L. and Abiodun, B. J. (2015). Drought regimes in southern africa and how well gcms simulate them. Climate Dynamics, 44:1595-1609. doi:10.1007/s00382-014-2325-z.

[98] van Dijk, A. I. J. M., Beck, H. E., Crosbie, R. S., de Jeu, R. A. M., Liu, Y. Y., Podger, G. M., Timbal, B., and Viney, N. R. (2013). The millennium drought in southeast Australia (20012009): Natural and human causes and implications for water resources, ecosystems, economy, and society. Water Resources Research, 49(2):1040-1057. doi:10.1002/wrcr.20123.

[99] Van Loon, A. F. (2015). Hydrological drought explained. WIREs Water, 2:359-392. doi:10.1002/wat2.1085.

[100] Van Loon, A. F., Stahl, K., Di Baldassarre, G., Clark, J., Rangecroft, S., Wanders, N., Gleeson, T., Van Dijk, A. I. J. M., Tallaksen, L. M., Hannaford, J., Uijlenhoet, R., Teuling, A. J., Hannah, D. M., Sheffield, J., Svoboda, M., Verbeiren, B., Wagener, T., and Van Lanen, H. A. J. (2016). Drought in a human-modified world: reframing drought definitions, understanding, and analysis approaches. Hydrology and Earth System Sciences, 20(9):3631-3650. doi:10.5194/hess20-3631-2016.

[101] Van Loon, A. F., Tijdeman, E., Wanders, N., Van Lanen, H. A., Teuling, A. J., and Uijlenhoet, R. (2014). How climate seasonality modifies drought duration and deficit. Journal of Geophysical Research: Atmospheres, 119(8):4640-4656. doi:10.1002/2013JD020383.

[102] Verdin, J., Funk, C., Senay, G., and Choularton, R. (2005). Climate science and famine early warning. Philosophical Transactions of the Royal Society B: Biological Sciences, 360(1463):21552168. 10.1098/rstb.2005.1754.

[103] Vicente-Serrano, S. M., Beguería, S., and López-Moreno, J. I. (2010a). A multiscalar drought index sensitive to global warming: The standardized precipitation evapotranspiration index. Journal of Climate, 23(7):1696-1718. doi:10.1175/2009JCLI2909.1.

[104] Vicente-Serrano, S. M., Beguería, S., López-Moreno, J. I., Angulo, M., and El Kenawy, A. (2010b). A new global $0.5^{\circ}$ gridded dataset (1901-2006) of a multiscalar drought index: Comparison with current drought index datasets based on the palmer drought severity index. Journal of Hydrometeorology, 11(4):1033-1043. doi:10.1175/2010JHM1224.1.

[105] Werth, S., White, D., and Bliss, D. W. (2017). GRACE detected rise of groundwater in the Sahelian Niger River Basin. Journal of Geophysical Research: Solid Earth, page 2017JB014845. doi:10.1002/2017JB014845. 
874

875

[106] White, W. B., Gershunov, A., Annis, J. L., McKeon, G., and Syktus, J. (2004). Forecasting Australian drought using Southern Hemisphere modes of sea-surface temperature variability. International Journal of Climatology, 24(15):1911-1927. doi:10.1002/joc.1091.

[107] Wold, S., Sjöström, M., and Eriksson, L. (2001). PLS-regression: a basic tool of chemometrics. Chemometrics and Intelligent Laboratory Systems, 58(2):109 - 130. doi:10.1016/S01697439(01)00155-1.

[108] Yang, Y., Long, D., Guan, H., Scanlon, B. R., Simmons, C. T., Jiang, L., and Xu, X. (2014). GRACE satellite observed hydrological controls on interannual and seasonal variability in surface greenness over mainland Australia. Journal of Geophysical Research: Biogeosciences, 119(12):2245-2260. doi:10.1002/2014JG002670. 